\title{
Complementary analyses of aging in a commercial LiFePO4/graphite 26650 cell
}

Scipioni, Roberto; Jørgensen, Peter S.; Stroe, Daniel I.; Younesi, Reza; Simonsen, Søren B.; Norby, Poul; Hjelm, Johan; Jensen, Søren H.

\section{Published in:}

Electrochimica Acta

Link to article, DOI:

10.1016/j.electacta.2018.07.124

Publication date:

2018

Document Version

Peer reviewed version

Link back to DTU Orbit

Citation (APA):

Scipioni, R., Jørgensen, P. S., Stroe, D. I., Younesi, R., Simonsen, S. B., Norby, P., Hjelm, J., \& Jensen, S. H. $(2018)$. Complementary analyses of aging in a commercial LiFePO 4 /graphite 26650 cell. Electrochimica Acta, 284, 454-468. https://doi.org/10.1016/j.electacta.2018.07.124

\section{General rights}

Copyright and moral rights for the publications made accessible in the public portal are retained by the authors and/or other copyright owners and it is a condition of accessing publications that users recognise and abide by the legal requirements associated with these rights.

- Users may download and print one copy of any publication from the public portal for the purpose of private study or research.

- You may not further distribute the material or use it for any profit-making activity or commercial gain

- You may freely distribute the URL identifying the publication in the public portal 


\section{Accepted Manuscript}

Complementary analyses of aging in a commercial $\mathrm{LiFePO}_{4} / \mathrm{Graphite}^{26650}$ cell

Roberto Scipioni, Peter S. Jørgensen, Daniel I. Stroe, Reza Younesi, Søren B.

Simonsen, Poul Norby, Johan Hjelm, Søren H. Jensen

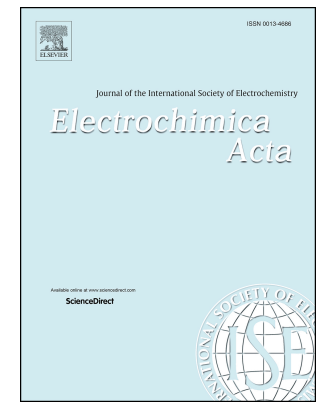

PII:

$$
\text { S0013-4686(18)31629-3 }
$$

DOI:

10.1016/j.electacta.2018.07.124

Reference: $\quad E A 32321$

To appear in: Electrochimica Acta

Received Date: 7 May 2018

Revised Date: 16 July 2018

Accepted Date: 17 July 2018

Please cite this article as: R. Scipioni, P.S. Jørgensen, D.I. Stroe, R. Younesi, Sø.B. Simonsen, P. Norby, J. Hjelm, Sø.H. Jensen, Complementary analyses of aging in a commercial $\mathrm{LiFePO}_{4} / \mathrm{Graphite}$ 26650 cell, Electrochimica Acta (2018), doi: 10.1016/j.electacta.2018.07.124.

This is a PDF file of an unedited manuscript that has been accepted for publication. As a service to our customers we are providing this early version of the manuscript. The manuscript will undergo copyediting, typesetting, and review of the resulting proof before it is published in its final form. Please note that during the production process errors may be discovered which could affect the content, and all legal disclaimers that apply to the journal pertain. 


\section{Complementary Analyses of Aging in a Commercial $\mathrm{LiFePO}_{4} / \mathrm{Graphite} 26650 \mathrm{Cell}$}

Roberto Scipioni $^{\mathrm{a}, \mathrm{b}, * \text {, Peter S. Jørgensen }}{ }^{\mathrm{a}}$, Daniel I. Stroe ${ }^{\mathrm{c}}$, Reza Younesi ${ }^{\mathrm{d}}$, Søren B. Simonsen ${ }^{\mathrm{a}}$, Poul Norby ${ }^{\text {a }}$, Johan Hjelm ${ }^{\text {a }}$, and Søren H. Jensen ${ }^{\mathrm{a}, * *}$

${ }^{a}$ DTU Energy, Department of Energy Conversion and Storage, Technical University of Denmark, Frederiksborgvej 399, 4000 Roskilde, Denmark

${ }^{\mathrm{b}}$ Department of Material Science and Engineering, Northwestern University, 2220 Campus Drive, Evanston, IL 60208, USA

${ }^{c}$ Department of Energy Technology, Aalborg University, Fredrik Bajers Vej 5, 9100 Aalborg, Denmark

d Department of Chemistry, Ångström Laboratory, Uppsala University, SE-751 21 Uppsala, Sweden

Keyword: Li-ion Battery; Cathode Electrolyte Interface; Electrochemical Impedance Spectroscopy; Degradation Mechanisms; Focused Ion Beam.

Corresponding author: (*) roscip@northwestern.edu (Roberto Scipioni), (**) shjj@dtu.dk (Søren Højgaard Jensen)

ABSTRACT: In this work we investigate the electrode degradation mechanisms in a commercial 2.5 Ah $\mathrm{LiFePO}_{4} /$ graphite 26650 cylindrical cell. Aged and fresh electrode samples were prepared by cycling two cells respectively five and $22 \mathrm{k}$ times. Subsequently the cells were disassembled in a glovebox and the electrode samples were prepared for electrochemical testing in a 3-electrode setup, and for characterization with XRD, XPS and low-kV FIB/SEM tomography. A $1 \mu \mathrm{m}$ thick CEI (cathode electrolyte interface) layer was observed at the electrode/electrolyte interface of the aged $\mathrm{LiFePO}_{4}$ electrode. Relative to the fresh $\mathrm{LiFePO}_{4}$ electrode, the aged electrode exhibited a larger series resistance which indicates the observed degradation layer increases the ionic resistance. In addition, micron-sized agglomerates, probably a mixture of carbonaceous material and decomposition products from the electrolyte, were observed at the electrode/electrolyte interface of the aged graphite electrode. These layers may contribute significantly to the loss of lithium inventory (LLI) in the cell, and to the loss of active material (LAM) in the graphite electrode. Low-voltage FIB/SEM tomography was used to detect local charging effects of graphite particles in the carbon electrode, an effect of poor dissipation of the electric charge to the ground after the sample interaction with the electron beam. The charging effects were primarily observed in 
the aged electrode and most of the locally charged particles were found to be close to the electrode/electrolyte interface, indicating a poorly percolating graphite network near this interface.

\section{- INTRODUCTION}

Lithium ion batteries (LIBs) span a broad range of applications from portable devices to electric vehicles (EVs) [1], [2]. However, limited lifetime is still a challenge for several LIB materials and the relation between degradation mechanisms and loss of performance is still not fully understood.

Despite its poor ionic and electronic conductivity $\mathrm{LiFePO}_{4}(\mathrm{LFP})$ is one of the more interesting cathode materials for lithium-ion batteries due to its relatively high cycle-ability and safety [3], [4]. To increase electron percolation in the electrode, the LFP is usually mixed with a carbonaceous additive such as carbon black. Graphite ( $\mathrm{Gr}$ ) is one of the early anode materials for commercial LIBs and it is still one of the most used anode materials [5]. Gr has a layered structure and is able to intercalate lithium ions between the graphitic layers. A solid electrolyte interphase (SEI) layer, with a thickness in the range of $10-100 \mathrm{~nm}$, needs to be formed on the anode/electrolyte interface to protect the anode from solvent intercalation, resulting in exfoliation of the graphite, and to protect the electrolyte from decomposition [6]-[10]. An analogous less studied layer, called cathode electrolyte interface (CEI) layer, is also formed on the positive electrode surface and is usually thinner $\left(\sim 5 \mathrm{~nm}\right.$ for $\left.\mathrm{LiFePO}_{4}\right)$ than the SEI layer on the negative electrode [11]-[14].

Several studies have, in lab scale, examined the degradation mechanisms of LFP [15]-[18] and Gr electrodes [19]-[21], and various models have been presented to predict performance and lifetime of commercial $\mathrm{LiFePO}_{4} /$ graphite cells [22]-[25]. Loss of lithium inventory (LLI), loss of active material (LAM), loading mismatching between electrodes and decrease of the active electrode surface area are among the most common degradation processes responsible for the performance loss of Li-ion batteries [26]. However, strong links between several of the observed degradation mechanisms and the operation of the battery are still not fully established. It is therefore important to enhance these links by relating the morphological changes in the battery electrodes with the battery use. Very few studies are instead found on the evolution of the CEI layer on the positive electrode surface and they all include the use of surface sensitive techniques which only permit to analyze the layer within few nanometers of depth [11]-[14]. Even fewer investigations of the CEI layer after long-term battery cycling have been reported, and refer to solid state [27] and high voltage batteries [28].

This paper presents a comparative study of a fresh and a cycling-aged commercial $\mathrm{LiFePO}_{4} /$ graphite 26650 cylindrical cell. The morphology changes in the electrodes due to cycling are characterized by a palette of complementary analysis techniques such as X-ray diffraction (XRD), X-ray Photoelectron Spectroscopy (XPS), Impedance spectroscopy and low-kV FIB/SEM tomography. The latter technique was developed to observe the electron percolation in SOFC anode Ni-networks [29] and has later been used to study the electron percolation in a laboratory $\mathrm{LiFePO}_{4} / \mathrm{CB}$ electrode [17], [30]. Here we use it to examine the electron percolation in the 
commercial graphite electrodes, in order to identify disconnected particles in the aged anode. Conventional FIB/SEM tomography is used to study morphological degradation and the evolution of the electrode/electrolyte interface in both the LFP and Gr electrodes.

\section{EXPERIMENTAL}

Battery cycling. Two commercial $\mathrm{LiFePO}_{4} /$ Graphite 26650 cylindrical cells with a nominal capacity of $2.5 \mathrm{Ah}$ were tested and characterized. The first battery was used as reference and labeled "F26650". It was cycled five times between 0\% and 100\% state-of-charge at room temperature at a constant C-rate of $0.1(250 \mathrm{~mA})$. The second battery labeled "A26650", was cycled 22000 times between $25 \%$ and $75 \% \mathrm{SOC}$ at room temperature but at a constant C-rate of $4(10 \mathrm{~A})$. The $4 \mathrm{C}$ charge-discharge (25-75\%) protocol was chosen because provides a very low degradation per $\mathrm{kWh}$ stored and represents relevant operation conditions without compromising the possibility for analysis and relating the observed degradation mechanisms with the test conditions. The test conditions are outlined in Table 1 and described in further detail below.

Battery disassembly. X-ray computed tomography (X-ray CT) was conducted on the batteries in part to prepare a suitable opening procedure. Further before disassembling the fresh and aged battery they were characterized with galvanostatic cycling with potentiostatic limitation (GCPL) and electrochemical impedance spectroscopy (EIS). The characterization methods are described in detail below. After X-ray CT, GCPL and EIS the two cylindrical cells were discharged to $2.8 \mathrm{~V}$ at $250 \mathrm{~mA}$.

The two batteries were disassembled in an argon filled glovebox and the positive and negative electrodes were unrolled. The cylindrical cells consist of a $1.5 \mathrm{~m} \mathrm{LiFePO} /$ carbonaceous additive positive electrode cast on both sides of an aluminum foil, a $1.5 \mathrm{~m}$ graphite ( $\mathrm{Gr}$ ) negative electrode cast on both sides of a copper foil and 2 polymeric separators soaked with liquid electrolyte. The total area of each of the battery electrodes and separators was $1950 \mathrm{~cm}^{2}$. The battery configuration is schematically presented in Fig. 1. The carbonaceous additive in the positive electrode is unknown. In order to distinguish the additive from the graphite in the negative electrode we refer to the additive with " $\mathrm{CB}$ " and to the graphite in the negative electrode with "Gr".

For the fresh battery, F26650, neither the anode nor the cathode foil showed any visible color difference between the various parts of the electrode; the part near the core of the battery and the part of the electrode near the skin of the battery as well as the edge and center parts looked the same. In contrast, a color difference was observed between the skin and the core part of the anode foil from A26650. As seen in the photos in the bottom part of Fig. 1, the anode foil is characterized by a blue shadowed region in the part of the foil close to the skin of the battery and a red region close to the core. In the presented photos the color saturation is increased to improve the visibility of the blue and the red region. The color covers almost completely the anode foil, with the exception of the sides of the electrode, where the original dark grey color of graphite is observed. Furthermore the edges appeared drier than the center regions, barely wetted by the electrolyte. 
Sample set preparation. From each cylindrical cell the two electrode foils were rinsed with diethyl carbonate and vacuum dried at $120^{\circ} \mathrm{C}$ for $2 \mathrm{~h}$ in order to remove the liquid electrolyte. From the four foils ten sample sets were cut. Each sample set consisted of several samples cut from proximately the same place in the foil. From F26650 two sample set were cut. One set from the cathode foil (labeled LFP_F) and one set from the anode foil (labeled Gr_F). From A26650 four sample sets were cut from the anode and four from the cathode. The sample sets were cut from the skin and core at the edge and center, respectively. The sample sets are labeled with respect to their original position in the foil: E.g. "_CE" refer to "Core, Edge" whereas "_SC" refer to "Skin, Center". An overview of the sample sets is given in the lower part of Table 1. The positioning of skin, center, core and edge are indicated in Fig. 1. Samples from each sample set were prepared for microscopy, XRD, XPS analysis, lithium dendrite tests and electrochemical testing.

\section{Characterization methods.}

X-ray computed tomography (X-ray CT). The fresh and aged batteries were characterized using x-ray computed tomography (CT) scans conducted with a lab-based Nikon Metrology XT H 225 ST $\mathrm{CT}$ scanner using a $\mathrm{W}$ reflection target at a power of $30 \mathrm{~W}$. The scan was performed at a voltage of $200 \mathrm{kV}$, with a $0.5 \mathrm{~mm} \mathrm{Cu}$ filter, an exposure time of $0.5 \mathrm{~s}$ and a total of 1572 projections over a $360^{\circ}$ rotation, resulting in a pixel resolution in the x-ray projection of $100 \mu \mathrm{m}$. The recorded data were reconstructed using a Feldkamp-Davis-Kress reconstruction algorithm. The CT scans didn't seem to reveal any difference between the aged and the fresh battery. For this reason only the CT scan of the fresh battery is presented here.

Galvanostatic Cycling with Potentiostatic Limitation (GCPL). F26650 was cycled five times between $2.8-3.6 \mathrm{~V}$ (the charge and discharge cut-off voltages are specified by the commercial supplier, i.e. here defined as $0 \%$ and $100 \%$ SOC, respectively) at room temperature and a nominal C-rate of $0.1 \mathrm{C}(250 \mathrm{~mA})$. Before disassembly, A26650 was characterized with the same GCPL cycle conditions.

The electrode samples for the GCPL tests consisted of circular disk electrodes with a diameter of $18 \mathrm{~mm}\left(\right.$ area $\left.=2.55 \mathrm{~cm}^{2}\right)$ that were punched out of the foils. These samples were scratched with a spatula to remove the electrode layer on one side of the current collector layer. Subsequently the samples were used for electrochemical testing in an EL-CELL $®$ ECC-Combi 3-electrode setup using a lithium metal foil counter electrode, a lithium metal reference electrode and a glass fiber separator soaked with a standard $1 \mathrm{M} \mathrm{LiPF}_{6}$ in $1: 1 \mathrm{EC} / \mathrm{DMC}$ electrolyte.

The samples were fully charged and discharged at approximately $0.1 \mathrm{C}$ in order to determine the remaining capacity. More specifically the LFP electrode samples were cycled between $3.0-3.6 \mathrm{~V}$ vs $\mathrm{Li}(\mathrm{m})$ with a constant current of $330 \mu \mathrm{A}$ (corresponding to a C-rate of 0.1 (calculated for the fresh electrode), considering that its surface area is $2.55 \mathrm{~cm}^{2}$ and that the unrolled battery electrode was $1950 \mathrm{~cm}^{2}$ ). Further the $\mathrm{Gr}$ electrodes were cycled between $0.01 \mathrm{~V}$ and $0.5 \mathrm{~V}$ vs $\mathrm{Li}(\mathrm{m})$, also at $330 \mu \mathrm{A}$. 
Incremental Capacity (IC). IC analysis is a useful technique that allows to distinguish the changes in the cell voltage and understand the electrochemical behavior of the cell. It converts the voltage plateaus, usually associated with phase transformations, or the inflection points, associated with solid solutions, into distinguishable peaks [31]. Here we use the IC analysis in a 3-electrode configuration to investigate the redox activity of the single electrodes and to transform the flat charge/discharge curves in $\mathrm{dQ} / \mathrm{dV}$ peaks, each representative of a particular electrochemical process. These peaks have different shape, intensity and position and are associated with phase transformations inside the cell [32], [33].

Electrochemical Impedance Spectroscopy (EIS). EIS measurements on F26650 and A26650 were conducted from $10 \mathrm{kHz}$ to $1 \mathrm{mHz}$ (10 pts per decade) and with an amplitude of $\pm 10 \mathrm{mV}$. All measurements were performed at room temperature, 50\% SOC, and at OCV after the cell had reached steady state defined by a voltage change rate $<5 \mathrm{mV} / \mathrm{h}$.

The spectra were modeled using an equivalent circuit model (ECM) previously developed for this type of battery [34]. The ECM is composed of two distinguished transmission line models (TLMs) in series to model separately the two porous electrodes (LFP and Gr) [35]-[37]. TLM $\mathrm{Gr}_{\mathrm{Gr}}$ includes a Meyers (case 2) equivalent circuit [38] to model the impedance response from $\mathrm{Li}^{+}$ diffusion in a graphite particle and the graphite particle/electrolyte interface where the particles are covered with a thin ion conducting layer (n.b. SEI on graphite). SEI layer resistance $R_{S E I}$, charge transfer resistance $R_{c t}$, double layer capacitance $C_{d l}$ and Li diffusion $D_{L i}$ within each graphite particle are calculated from best fit parameters obtained using CNLS fitting of the model to the experimental data as described in [22]. TLM $\mathrm{LFP}_{\text {is }}$ is characterized by a Randles circuit at the $\mathrm{LiFePO}_{4} /$ electrolyte interface: $R_{c}, C_{d l}$ and $D_{L i}$ values for LFP are also obtained from the best fit parameters of the model to full cell impedance spectra. The two TLMs involves among other parameters pore length $L$ and particle radius $r$, which were obtained by analysis of the 3D reconstruction of the electrode microstructure created by FIB/SEM tomography, and are used in the calculations of the electronic resistance $R_{e l}$ of the electrodes (reflecting the integrity of the percolating carbon network) and ionic resistance $R_{i o n, L}$ of the electrolyte filled pore phase

Lithium Plating Test. Samples for the lithium plating test were square pieces cut from the electrode foils. The samples were prepared in the argon filled glove box, sealed under vacuum in a pouch bag and transferred outside. The samples were tested for lithium plating and dendrite formation by adding few drops of water on the sample surface. Any Li(s) reacts spontaneously with water forming $\mathrm{LiOH}$ (aq) and hydrogen. As such hydrogen bubbles indicate Li(s) at the sample surface. The test was conducted immediately after the sample was pulled out from the pouch bag, in order to minimize the oxidation of some possible lithium metal on the electrode surface in contact with the air.

FIB/SEM tomography. The ten electrode samples (Table 1) prepared for the FIB/SEM tomography were vacuum infiltrated with a silicon resin (Wacker Chemie) for 30 minutes. The silicon resin improves phase contrast between CB particles and pores [39]. Subsequently the 
samples were infiltrated with epoxy resin to enable high-quality grinding and polishing of the sample.

The FIB tomography and SEM imaging was carried out on a Zeiss 1540XB CrossBeam microscope, using a lateral E-T (Everhart-Thornley) detector and an In-lens detector. A Gallium FIB slicing probe of $2 \mathrm{nA}$ was used to mill the LFP electrodes. For the softer $\mathrm{Gr}$ electrodes the current had to be reduced to $1 \mathrm{nA}$ to enable high-quality imaging. Table 2 shows the volume and voxel sizes of the ten 3D datasets. In the table the slice thickness is given as the " $X$ " of the voxel size. The $\mathrm{Y}$ and $\mathrm{Z}$ refer to respectively the pixel width and height in the SEM images. The slice thickness is calculated by measuring the progress of the milling front in each image during the stack alignment post processing step.

The LFP particles in the cathode are much smaller (around one-tenth in size) than the $\mathrm{Gr}$ particles in the anode. In order to perform an accurate image segmentation of LFP particles it was necessary to collect high-resolution images with increased magnification as can be seen from table 2.

Low-voltage analysis. The FIB/SEM serial sectioning imaging has been performed and combined with a low-voltage SEM $(1 \mathrm{kV})$ scanning in order to identify the electron percolation in the CB and Gr network. Low-voltage analysis was first described and used by Thydén et al. [29] to identify electron percolation in SOFC anode Ni-network. Secondary electrons (SEs) emitted from the sample have by definition energies $<50 \mathrm{eV}$. At low voltage several materials have an SE yield different than 1 [40], [41], resulting in either positive or negative charge occurring at the sample surface. If the material is insulating or not connected to ground, it will not be able to dissipate this charge (to ground). Instead an equilibrium is rapidly established where the charge (electrons) hitting the sample equals the emitted charge (electrons). The difference in emitted electrons can be detected by the microscope In-lens detector that is sensitive to low energy electrons, giving rise to contrast between percolated and isolated particles.

The combination of low-voltage SEM and FIB/SEM have recently been used for 3D electron percolation analysis of a $\mathrm{CB}$ additive in a laboratory $\mathrm{LiFePO}_{4} / \mathrm{CB}$ positive electrode [17], [30].

Image processing. Segmentation of the 3D FIB/SEM image data was performed with the program ImageJ (NIH). Because of uneven illumination, setting a single threshold for all the micrographs was not feasible. Therefore the Sauvola algorithm [42], [43] was used to perform local thresholds of the data.

The particle and void size distributions (PSD) in all electrode samples were analyzed based on the method introduced by Münch et al. [44]: The segmented 3D volumes are filled with overlapping spheres of the largest radius that will fit into each part of the volume structure. Each voxel is assigned the radius of the largest sphere that overlaps the voxel. The cumulative PSD is then obtained as the distribution of the voxel sphere radii.

Visualizations of the 3D reconstructions of the analyzed data were performed with the program Avizo (FEI). 
X-ray photoelectron spectroscopy (XPS). XPS measurements were conducted at an in-house spectrometer (PHI 5500) using monochromatized Al Ka radiation. The XPS spectra were energy calibrated by setting the adventitious carbon peak to $285 \mathrm{eV}$. The XPS samples were also prepared in the argon filled glove box. They were sealed under vacuum in a pouch bag and transferred into the analyzing chamber of the XPS instrument without any exposure to atmosphere using a special transfer cup. No edge samples were analyzed with XPS.

X-ray diffraction (XRD). The XRD samples were prepared by scratching off the electrode from the current collector, grounding it with a mortar and sealing in a borosilicate glass capillary in argon atmosphere, to avoid any air contamination. Beamline BL04 at the ALBA Synchrotron was used for the XRD measurements of the ten electrode samples with a wavelength of $0.4950 \AA$. The data were normalized to the background and fitted in the software Winpow [45], for Rietveld refinements, as single pseudo-Voigt peaks and a background described by a $5^{\text {th }}$ order Chebyshev function.

\section{- RESULTS}

X-ray computed tomography (X-ray CT). The results from the x-ray tomography show the placement of four current collector tabs at the edge of the battery roll (Fig. 2). Further, the gas vent system is seen at the top of the battery. The vent system is used to vent of gasses originating from electrolyte decomposition. A video of the X-ray tomography is provided in the supplemental info.

Galvanostatic Cycling with Potentiostatic Limitation (GCPL) and IC analysis. Before disassembly F26650 and A26650 was cycled a couple of times at $250 \mathrm{~mA}$, in order to quantify the capacity fade. Fig. 3a shows the charge/discharge curves for F26650 and A26650. The measured charge capacity is scaled to the electrode area $\left(1950 \mathrm{~cm}^{2}\right)$. Fig. $3 \mathrm{~b}$ and $3 \mathrm{c}$ show the area specific charge/discharge curves for the five LFP/CB and the five Gr electrodes, respectively.

The total specific discharge capacity in F26650 is $1.27 \mathrm{mAh} \mathrm{cm}^{-2}$, while A26650 shows a specific discharge capacity of around $0.98 \mathrm{mAh} \mathrm{cm}^{-2}$, indicating a capacity loss equal to $22.5 \%$. The capacities measured from the GCPL cycles are summarized in Table 3. For the LFP samples, the $\mathrm{LiFePO}_{4}[\mathrm{~mol} . \%]$ is calculated as the ratio between the charge capacity and the discharge capacity. Similar for the Coulumbic efficiency for the Gr samples.

The charge/discharge curves for the LFP electrode samples (Fig. 3b) show a flat voltage plateau at around $3.45 \mathrm{~V}$, typical for $\mathrm{Li}_{1-\mathrm{x}} \mathrm{FePO}_{4}$ with $0 \leq \mathrm{x} \leq 1$ vs. $\mathrm{Li}(\mathrm{m})$ [46], [47]. In the first cycle, the charge capacity for LFP_F is $1.32 \mathrm{mAh} \mathrm{cm}^{-2}$ which is comparable to the F26650 charge capacity (Fig. 3a), while the discharge capacity is $1.46 \mathrm{mAh} \mathrm{cm}^{-2}$. The ratio between the first charge and discharge capacity correspond to the amount of $\mathrm{LiFePO}_{4}$ in the electrode (Table 3).

LFP_SC and LFP_CC electrodes show a charge capacity of 0.83 and $0.73 \mathrm{mAh} \mathrm{cm}{ }^{-2}$ respectively, equal to the $57 \%$ and $50 \%$ of the discharge capacity of LFP_F. However, the discharge curves for the aged electrodes completely resemble the initial capacity, showing that there are no electrochemically inactive LFP particles in the two samples. A little step in lithium intercalation is 
observed in the discharge curves of LFP_SC and LFP_CC, as shown in the inset in Fig. 3b. The zoomed view shows also that the over polarization for the aged samples is about $5 \mathrm{mV}$ higher than that for LFP_F. Also LFP_SE and LFP_CE show a smaller charge capacity than the subsequent discharge capacity, although the discharge capacity doesn't fully reach that of LFP_F.

All the aged Gr samples had less capacity than the fresh sample (Fig. 3c). Further, a difference between charge and discharge curves equal to $10-15 \%$ is observed for all the aged samples.

Fig. 3d show the IC curves for the fresh and aged cylindrical cell. The typical 5 peaks of an LFP/Gr cell are observed, which are reported to correspond to the intercalation stages of lithium in the graphite electrode convoluted with a single peak relative to the flat plateau of the $\mathrm{LiFePO}_{4} / \mathrm{FePO} 4$ phase transformation [32], [33]. It is possible to observe a decrease in intensity and shift toward lower voltage for peak 1 during discharge. Peak 2 is instead characterized by only a smaller intensity, while no changes are observed for the other peaks.

The IC curves of the LFP electrode (Fig. 3e) shows the typical peak for LFP at around $3.45 \mathrm{~V}$ [48]. It is interesting to notice that during discharge, the peak tends to decrease in intensity and shift to lower voltage for the aged samples. Further an additional peak is observed for the samples harvested from the center.

The graphite electrodes IC curves (Fig. 3f) shows different peaks, corresponding to the different intercalation stages. All the aged samples are characterized by a reduction in the peak intensities and a shift toward higher voltage.

Electrochemical Impedance Spectroscopy. The impedance spectra recorded on F26650 and A26650 at 50\% SOC are presented in Fig. 4. The spectra were modeled using an ECM previously developed for this type of battery [34]. The model results are presented in Table 4. Fig. 4a,b show the Nyquist and Bode plots of the two spectra, with relative fittings. The series resistance is observed to be larger for A26650 than for F26650 (Fig. 4a and Table 4). In contrast to this, the impedance around $50 \mathrm{~Hz}$ is observed to be smaller for A26650 than for F26650 (inset in Fig. 4b). Finally the low-frequency branch is larger for A26650 than for F26650.

Nyquist and Bode plots of the impedance spectra for the fresh (Fig. 4c,e) and the aged (Fig. 4d,f) cell, after removal of the wire inductance and including the elements of the ECM, are also shown. The polarization processes observed at different frequency ranges, could be ascribed to different processes in the cylindrical cells. The semicircle at relative high-frequency (red solid line) represents the aluminum current collector polarization [49], [50], and the resistance associated with it is observed to slightly increase with degradation, as shown in the Bode plots (Fig. 4e,f) and reported in Table 4. The mid- and low- frequency part are modelled by two TLMs for the LFP and Gr porous electrodes. The process observed at $50 \mathrm{~Hz}$, ascribed to the resistance furnished by the SEI layer on the graphite particles, shows a smaller $R_{S E I}$ in the aged cell. The low frequency branch is modeled by the two TLMs. Gr electrode in A26650 is characterized by an increase in the charge transfer resistance $R_{c t}$ and a huge drop in $D_{L i}$, observed to be an order of magnitude smaller (Table 4). No big changes are observed for the ion resistance in the infiltrated pores $R_{i o n, L}$. $R_{c t}$ slightly 
increases in the aged LFP electrode, while no change in $\mathrm{Li}$ diffusion in the $\mathrm{LiFePO}_{4}$ electrode are noticed. $R_{i o n, L}$ and $R_{e l}$ slightly raises with degradation.

Lithium plating test. 10 samples were tested for lithium plating and dendrite formation by adding few drops of water on the sample surface. Both the fresh samples from F26650 (Fig. 5a,f) had no reaction after water addition. The aged Gr electrode samples from the skin (Fig. 5b,c) had a fizzing reaction while the aged Gr samples collected from the core (Fig. 5d,e) were characterized by a stronger bubbling. No bubbling was observed for the four aged LFP electrodes (Fig. 5g-j).

FIB/SEM. Figure 6 shows cross-sectional SEM images of the 10 electrode samples from each of the sample sets specified in Table 1 . The images were recorded with a lateral E-T detector and $1 \mathrm{kV}$ acceleration voltage after FIB milling. The top of Figure 6 displays five circles with the numbers 1,2 and $3 a, 3 b$, and 4 . The SEM images are vertically arranged such that (1) indicates an area in the SEM image showing a current collector, (2) indicates an area showing the anode, (3a) displays the region adjacent to the anode where the electrolyte filled separator sat before the battery was disassembled, (3b) show the same as 3a, but adjacent to the cathode, and (4) shows the cathode. The top part of the individual SEM images shows a bright region which is the polished sample surface. Three different phases could be distinguished in the LFP samples: light gray $\mathrm{LiFePO}_{4}$ particles, dark gray pores (infiltrated with silicon resin) and black CB particles. In LFP_F (Fig. 6b) some of the LFP and CB particles are separated from the rest of the electrode. The detachment possibly occurred during sample preparation. LFP_SC and LFP_CC (Fig. 6h,j) show a dark layer at the electrode/electrolyte interface assumed to be carbon and CEI layer formed by electrolyte decomposition products. This layer is thickest and most homogeneous in LFP_CC. The remaining separator area in (3b) is filled with silicon resin (dark gray bulk) or epoxy resin (black bulk).

Only two phases could be distinguished in the Gr samples: dark graphite particles and gray pores infiltrated with silicon resin. The larger darker parts to the right of the electrode areas are filled with epoxy resin, the larger brighter areas with silicon resin. All the electrodes are characterized by a porous structure of graphite grains. However Gr_SC and Gr_CC show smaller graphite particles than Gr_F, as confirmed below with PSD. Additionally Gr_CC have big black agglomerates at the electrode/electrolyte interface.

Three-dimensional reconstruction and structure analysis. The three-dimensional reconstructions of the ten segmented datasets are shown in Fig. 7. Each dataset consists of a stack of images as those presented in Fig. 6, see detailed description in the experimental section. To highlight the electrode interior the reconstructed volume is only a part of the volume represented by the stack of images. In Fig. $7 \mathrm{Gr}$ samples are seen to the left and LFP electrodes to the right. The circled numbers in the top of the figure refer to the same areas as for Figure 6 . The sub-volumes labeled with (2) and (4) in Fig. 7 were used for the PSD analysis of active material, CB additive and pores. The sub-volumes (3a) and (3b) were only used for the PSD analysis of the agglomerates.

As can be seen from Figure 6 the microstructure is quite inhomogeneous and varies significantly in appearance between the analyzed locations. From the present analysis, we cannot say to which degree the observed differences are due to local variations in the structure or due to differences in 
the test conditions. This combined with the limited resolution and volume sizes means that only the particle size distribution results are included here.

For the LFP samples light gray particles represent LFP grains, black particles signify CB, and transparent blue show pores. For LFP_SC and LFP_CC a dark layer is observed at the electrode/electrolyte interface. The layer is approximately $0.5 \mu \mathrm{m}$ and $1 \mu \mathrm{m}$ thick for LFP_SC and LFP_CC respectively. The average sizes for particles, pores and agglomerates were retrieved from the reconstructions, and are presented in Table 5, the size distribution (PSD) for the LFP electrode is reported in Fig. 8a. Due to the high uncertainty on these values, no significant changes in particle size can be confirmed from this analysis.

For the Gr samples the orange region represents the copper current collector. In the electrode part two phases can be distinguished. Dark gray particles are graphite grains. Pores are represented as transparent blue. Large agglomerates with a diameter between 5-10 $\mu \mathrm{m}$ in diameter are seen at the Gr_CC electrode/electrolyte interface. The average sizes for particles, pores and agglomerates were retrieved from the reconstructions, and are presented in Table 5 and the size distribution of $\mathrm{Gr}$ particles (PSD) is reported in Fig. 8b. The average Gr particle size measured to be smaller in all four aged samples. However, the thinner volume analyzed in Gr_SE, Gr_CE and Gr_SC could affect the PSD calculation with a consequent underestimation of the average particle diameter. Accordingly, only Gr_F and Gr_CC are quantitively compared in the PSD analysis. The PSD analysis of the dark agglomerates only counts a few big particles and is consequently not very accurate.

Low-voltage analysis. Figure 9 shows cross-sectional In-lens images recorded at $1 \mathrm{kV}$ after FIB milling of the Gr electrodes. The low accelerating voltage enables a detection of charging effects on carbonaceous materials [17], [30]. Dark gray particles are graphite grains which are observed to dissipate electron charging (induced by the SEM electrode beam) to the ground. In contrast, light gray particles are graphite grains which show some local charging effects during the low-voltage imaging. Almost no graphite grains are observed to charge in Gr_F, and a higher amount of particles are observed to charge in the aged Gr samples in particular in the part of the electrodes closest to the electrode/electrolyte interface (dotted black circles in Fig. 9d,e). A movie showing the full FIB/SEM segmentation of Gr samples is provided in the supplemental info. The movie shows how the brightness flickers between charging and non-charging particles for several of the $\mathrm{Gr}$ particles in the aged electrode.

XPS. Figure 10 shows F 1s and O 1s spectra for fresh, skin center and core center samples collected from both LFP and Gr electrodes. As mentioned no edge samples were analyzed with XPS. The fluorine signal is mainly generated by the $\mathrm{PVdF}$ binder and $\mathrm{LiF}$ formed by decomposition of the $\mathrm{LiPF}_{6}$ salts (see the peak assignments in Figure 10a) [51], [52]. The peak at $685 \mathrm{eV}$, which represent $\mathrm{LiF}$, has high intensity on all the graphite samples and on LFP_CC. The O 1s spectra (Fig. 10b) contain at least two peaks, one at about $532 \mathrm{eV}$ attributed to $\mathrm{C}=\mathrm{O}$ bond in carbonates and carboxylates generated by decomposition of solvent, and another one at $534 \mathrm{eV}$ attributed to C-O 
containing species [53], [54]. All the LFP samples show the presence of $-\mathrm{CO}_{3}$ containing species on their surfaces, but a higher amount of $\mathrm{C}-\mathrm{O}$ species $(534 \mathrm{eV}$ peak) is observed in the aged samples.

X-ray diffraction. XRD analysis of the LFP samples are presented in Fig. 11a,b. The diffraction patterns were analyzed for peaks related to $\mathrm{LiFePO}_{4}$ and $\mathrm{FePO}_{4}$. From the Rietveld refinement the amount of $\mathrm{LiFePO}_{4}$ was retrieved. The results are presented in Table 6. Fig. 11a shows a zoom on the (020) reflection in LFP, and the (211) and (020) reflections in FP. The XRD patterns in Fig. 11a, normalized to the (020) reflection in LFP, show the decreasing $\mathrm{LiFePO}_{4} / \mathrm{FePO}_{4}$ ratio in the different regions of the aged electrode, as reported in Table 6. XRD patterns of the $\mathrm{Gr}$ samples are presented in Fig. 11c,d. From the Rietveld refinement no lithiated graphite was found (Table 6). The zoom on the peak in part c) shows peak broadening of (002) reflection in graphite, in particular for the Gr_SE and GR_CE samples. No significant changes in the unit cell parameters for $\mathrm{LiFePO}_{4}$, $\mathrm{FePO}_{4}$ and graphite are observed (Table 6).

\section{- DISCUSSION}

Morphological changes. No degradation to the LFP lattice seems to occur according to the cell parameter values calculated by XRD. Furthermore, results from EIS fitting show that the diffusivity of Li ions in the LFP does not change in the aged sample. A change in the heterogeneity of the CB network distribution is indicated by the increased electron resistance in the electrode $R_{e l}$, calculated in TLM $_{\mathrm{LFP}}$ by EIS modeling.

The most important degradation process seems to be the formation of a CEI layer [11]-[13], [17] at the electrode/electrolyte interface. The layer is possibly a mixture of carbon and electrolyte decomposition products [11]-[13], [17], [26], [30], [55] and is expected to partially block the electrolyte passage thereby increasing the ionic resistance. This increases the polarization of the aged electrodes during charge/discharge cycling, as shown by GCPL results in previous section and confirmed by the increased ohmic resistance $R_{E}$ in the impedance spectra of A26650. As mentioned, the layer at the electrolyte/electrode interface is probably composed by a mixture of $\mathrm{CB}$ and decomposition products from the electrolyte, i.e. Li-organic species, fluorophosphates and $\mathrm{LiF}$ [13] and could thus in part explain the loss of lithium inventory (LLI). This was confirmed by XPS results which showed a higher amount of $\mathrm{LiF}$ and alkoxides on the aged electrodes surface. No Li plating occur on the cathode CEI layer, as no bubble formation occurred after dropping water on the cathode samples surfaces (Fig. 5). The layer is found to be thickest in the sample collected from the core of the cylindrical battery, which could be an effect of the accelerated degradation of the electrolyte caused by the higher temperature [56], [57] developed in the core of the cylindrical cell [58].

FIB/SEM tomography of the Gr electrodes also revealed formation of large agglomerates at the electrode/electrolyte interface. They are most likely a mixture of SEI layer (LiF and carbonates), as confirmed by XPS analysis (Fig. 10). The Li plating test revealed bubble formation on the cycled Gr electrode samples (Fig. 5) which indicates substantial Li plating, in agreement with previous 
results [55], [59], [60]. Although lithiated graphite may react with water and form lithium hydroxide in the deeper part of the SEI layer [61], the observed bubbling reaction is most likely attributed to the presence of lithium metal on the surface: no lithiated graphite was indeed found by XRD and GCPL analysis. From the PSD analysis it is also seen that the graphite particles are significantly smaller in the aged samples than in Gr_F, in particular in the edges of the battery. This is confirmed by the XRD peak broadening analysis. The smaller particle size is probably an effect of cracking of Gr particles with cycling [62], [63].

Low-voltage charge contrast The low-voltage analysis was previously used to detect charging effect in the CB network of a laboratory LFP electrode to study the changes in the electron dissipation capability in the CB network [17], [30]. Similar to the cathode sample from F26650 the cathode samples from A26650 reveal no significant charging effects.

The low - kV FIB/SEM was useful to detect locally charged particles in the Gr samples. As shown in Fig. 9 (and in the full FIB/SEM dataset of Gr samples furnished in the supplemental info), from the identification of locally charged Gr particles in the negative electrode sample, a distinction between "percolating" and "non-percolating" graphite particles was possible. The bright graphite particles are predominantly found in the region of the electrode closest to the electrode/electrolyte interface. These charging effects are not fully understood yet, however they are believed to describe graphite particles that are disconnected from (or at least loosely connected with) the electron percolating network. Several Gr grains show in fact a flickering intensity between two consecutive images during the milling job. This is probably an effect of connection/disconnection of the same particle from the percolating network concurrently with the ion milling. Furthermore, cracking of graphite particles with cycling, as previously suggested by PSD calculation, would create new carbon/electrolyte interfaces which would be covered by SEI layer. The SEI layer is known to be electron insulating [64]-[66]. This would of course create new secondary smaller graphite grains and increase the amount of SEI layer in the Gr bulk, resulting in an increased electronic resistance.

Use of low - $\mathrm{kV}$ FIB/SEM analysis could be a good complementary technique to the conventional computed connectivity analysis [17], [30] for structures with features close to the resolution limit of the imaging technique.

Loss of Lithium Inventory (LLI) and Loss of Active Material (LAM) As discussed in the previous section, A26650 shows a capacity loss of $22.5 \%$ after being cycled 22000 at $4 \mathrm{C}$ between 25\% and 75\% SOC (Fig. 3a). The charge/discharge capacities of LFP_F and GR_F match the F26650 capacity well. The discharge capacity of LFP_F is 10\% higher than that of F26650, which is expected to account for the amount of lithium spent for the initial SEI layer formation at the graphite electrode [7]-[9].

The results from the IC analysis (Fig. 3d) indicate that LLI and LAM are the main causes of the capacity loss. As described in literature [67], LAM causes a loss in peak intensity in the IC analysis, while LLI results in a combined shift and loss in peak intensity. Both phenomena are observed for peak 1 and 2 (Fig. 3d). 
LLI is observed to be the main degradation occurring at the positive electrode. Similar to previous observations [26], [55] LFP_SC and LFP_CC show a lower capacity during the first charge (57 and 50\% of the fresh electrode capacity, respectively). This means that only a fraction of the LFP was fully lithiated to $\mathrm{LiFePO}_{4}$ during the final discharge and that a substantial part of the LFP remains as $\mathrm{FePO}_{4}$. After the first discharge both LFP_SC and LFP_CC are able to recover completely the initial capacity, also in agreement with previous observations [26], [55]. This shows that there are no electrochemically inactive parts of the material at the core, and that all the regions of the electrode are accessible to lithium ions. This suggests that almost no capacity fade occurs to the LFP electrode due to cycling. However, a higher polarization was observed in the aged electrodes (Fig. 3b). This is possibly related to a decreased electronic conductivity in the carbon phase and/or a decreased ionic conductivity in the electrolyte phase. The decreased ionic conductivity is most likely related to the partially blocking layer at the electrode/electrolyte interface on the aged samples (Fig. 7). The $\mathrm{LiFePO}_{4} / \mathrm{FePO}_{4}$ ratios calculated in the LFP samples after GCPL (Table 3) were found to be similar to the ones obtained from Rietveld refinements (Table 6). More specifically, LFP_F, LFP_SC and LFP_CC samples characterized by XRD were observed to have the same ratios (within 4\% difference) of the samples cycled by GCPL. Ratios for LFP_SE and LFP_CE XRD samples are 10\% and 16\% higher than the ratios obtained for the GCPL samples. This means that a part of the LFP electrode at the edge is electrochemically isolated and, even though the amount of "stranded" LFP could be detected by XRD, it still results in a permanent discharge capacity loss at the edges, as shown in Fig. $3 \mathrm{~b}$ and Table 3. The IC analysis for the LFP electrodes (Fig. 3e) confirms that LLI is the main aging mechanisms occurring at the cathode. The lower inset in Fig. 3e shows that the discharge peak is influenced by a combined shift to lower voltage and decrease in intensity for the aged samples [67]. The additional peaks observed for the most degraded samples harvested from the center are not fully understood. They could be attributed to an increasing amount of amorphous $\mathrm{LiFePO}_{4}$, known to insert lithium at a lower voltage [68], [69].

The capacity fade observed in the cylindrical cell is most likely due to the capacity fade of the $\mathrm{Gr}$ electrode. The charge capacity of the Gr samples was substantially decreased compared with that of GR_F in agreement with previous observations [26], [55]. Gr_CC had the lowest capacity followed by Gr_SC, Gr_CE, and Gr_SE. This indicates that the edges are substantially less degraded. The difference in electrode color is most likely related to this. For all the aged $\mathrm{Gr}$ samples the discharge (or lithiation) capacity of the first cycle was observed to be 10-15\% higher than the charge (or delithiation) capacity. This means that the majority of the lithium ions were extracted from the $\mathrm{Gr}$ electrodes during the final discharge before disassembling and all the regions are fully delithiated. Otherwise - as for the LFP samples - the discharging capacity would be substantially smaller than the subsequent charge capacity. On the contrary, it looks like an amount of lithium was spent to build additional SEI layer in the aged samples. The Rietveld refinement results confirm that the Gr samples are fully delithiated.

A possible explanation to the capacity fade in the Gr electrode is the combined loss of active material and loss of lithium inventory used to build new SEI layer [70]. Fracturing of graphite agglomerates, as observed by PSD analysis, will lead to the exposure of new surface to the 
electrolyte with consequent loss of lithium from the LFP electrode, spent to build additional SEI layer. Graphene layers exfoliation after particles and SEI fracturing is also considered a possible degradation mechanism [23], [71], [72]. The results from the IC analysis for the Gr electrodes (Fig. 3f) seems to confirm the LAM. A loss in peak intensities, proportional to the capacity loss, is indeed observed for all the aged samples. It is interesting to notice how all the aged samples present a shift to higher voltage during discharge. This reduction in the anode resistance could be explained by an increase of the surface area and/or cracking of the SEI layer.

Discharge mechanism at the edge The degradation mechanisms investigated in this manuscript find many similarities with the ones observed in previous works [26], [55]. However Klett et al [55] found that some of the graphite electrodes harvested from the edges were at a lithiation degree higher than expected. No lithiated graphite was found in any of our samples. The higher lithiation degree observed in [55] could probably be explained by the higher C-rate used to completely discharge the battery before disassembling (1.3C in Klett's work instead of $0.1 \mathrm{C}$ in our work). $D_{L i}$ in aged graphite electrode was observed to be an order of magnitude lower than in the fresh cell and a lower C-rate is then required to fully delithiate the Gr electrode. Furthermore, the edges of the electrodes are not in direct contact because of some void created by the thickness of the copper tabs, as shown in Fig. 2b. It would not be a significant issue if the cylindrical cell was filled with the electrolyte as in the fresh cell (Fig. 12a). However gases from electrolyte decomposition [70], [73] released via the gas vent, would result in dry electrodes, as observed at the edges after disassembling the cell. According to this, if an electrolyte connection is not guaranteed between anode and cathode (Fig. 12b), the lithium ion path from Gr to LFP during the discharge would be much longer and a slower C-rate is then needed to fully delithiate the graphite. A schematic representation of the Li ions path is shown in Fig. 12. Capillary forces and electrolyte wettability in the electrodes is believed to explain why the larger voids near the tabs dries before the micropores in the electrodes.

\section{- CONCLUSIONS}

In this work the electrode degradation mechanisms in a commercial $2.5 \mathrm{Ah} \mathrm{LiFePO}_{4} / \mathrm{Graphite}$ 26650 cylindrical cell were examined. Galvanostatic cycling with potentiostatic limitation (GCPL) shows that the extracted LFP electrode samples from the aged battery are not completely lithiated despite the battery being fully discharged before disassembling. A noticeable difference between the edge and center of the battery roll is observed. Loss of lithium inventory (LLI) contributes to the capacity loss observed in the aged $2.5 \mathrm{Ah}$ cell. This seems to be most extensive for the samples extracted from the center of the battery roll. Additionally, the core exhibits a higher LLI than the skin of the roll. After the first charge/discharge cycle the LFP samples extracted from the center of the aged battery roll were able to completely recover the initial capacity, showing that there are no electrochemically inactive regions in those samples. This is previously observed for the LFP electrodes. The LFP samples extracted from the edge of the roll only partially regained the full capacity. Graphite electrode samples from the aged battery roll (anodes) exhibit a significant 
capacity fade due to loss of active material (LAM) where the center part of the roll show more loss than the edge part, and the core show more loss than the skin.

FIB/SEM tomography analysis showed that the anode Gr particle size is smaller in the cycled battery than in the fresh battery whereas no significant change in cathode LFP particle size could be observed. The decrease in the Gr particle size could be an effect of mechanical stress during lithiation/delithiation process. The smaller Gr particle size in the aged anode is confirmed with XRD peak broadening. In addition, the cycling seems to produce a layer of what is believed to be electrode/electrolyte decomposition products at the LFP electrode/electrolyte interface. A decomposition layer is also produced at the electrode/electrolyte interface of the cycled anode. The layers at the anode and cathode electrode/electrolyte interfaces are composed of LiF and Li-organic species as shown by XPS analysis, and are believed to be the main degradation mechanism causing loss of lithium inventory (LLI) in the cylindrical cell. The layers are thicker on the core of the cylindrical cell, suggesting that the higher temperature accelerate the electrolyte decomposition. Gas evolution, and consequent drying of electrolyte, is believed to be an additional aging mechanism, since it affects the ionic pathway at the edges.

Low - kV FIB/SEM tomography was also used to study the electron percolation in the graphite network in 3D, and several graphite particles in the aged anode were found incapable of dissipating the electric charge induced by the microscope electron beam. This was predominantly observed in the region close to the electrode/electrolyte interface and could be an effect of cracking of $\mathrm{Gr}$ particles upon cycling. This correlates with the GCPL measurement which shows significant capacity loss for the cycled samples, i.e. it indicates loss of active material.

\section{- ACKNOWLEDGEMENT}

The authors gratefully acknowledge financial support from the Danish Strategic Research Council through the project "Advanced Lifetime Predictions of Battery Energy Storage" (contract no. 060300589B). Powder diffraction experiments were performed at BL04 - MSPD beamline at ALBA Synchrotron with the collaboration of ALBA staff. The 3D Imaging Centre at the Technical University of Denmark is gratefully acknowledged. Ilaria Ritucci is also gratefully acknowledged for the collection of photographs.

\section{- REFERENCES}

[1] M. Armand and J.-M. Tarascon, "Building better batteries.," Nature, vol. 451, no. 7179, pp. 652-657, 2008.

[2] B. Scrosati, J. Hassoun, and Y.-K. Sun, "Lithium-ion batteries. A look into the future," Energy Environ. Sci., vol. 4, no. 9, p. 3287, 2011. 
[3] A. K. Padhi, K. S. Nanjundaswamy, and J. B. Goodenough, "Phospho $\square$ olivines as Positive $\square$ Electrode Materials for Rechargeable Lithium Batteries," J. Electrochem. Soc., vol. 144, no. 4, pp. 1188-1194, 1997.

[4] Y. Wang, P. He, and H. Zhou, "Olivine LiFePO4: development and future," Energy Environ. Sci., vol. 4, no. 3, p. 805, 2011.

[5] Huggins, Advanced batteries, vol. 276. 2009.

[6] E. Peled and S. Menkin, "Review-SEI: Past, Present and Future," J. Electrochem. Soc., vol. 164, no. 7, pp. A1703-A1719, 2017.

[7] J. Yan, J. Zhang, Y. C. Su, X. G. Zhang, and B. J. Xia, "A novel perspective on the formation of the solid electrolyte interphase on the graphite electrode for lithium-ion batteries," Electrochim. Acta, vol. 55, no. 5, pp. 1785-1794, 2010.

[8] H. Wang, T. Umeno, K. Mizuma, and M. Yoshio, "Highly conductive bridges between graphite spheres to improve the cycle performance of a graphite anode in lithium-ion batteries," J. Power Sources, vol. 175, no. 2, pp. 886-890, 2008.

[9] A. a Franco, "Multiscale modelling and numerical simulation of rechargeable lithium ion batteries: concepts, methods and challenges," Rsc Adv., vol. 3, no. 32, pp. 13027-13058, 2013.

[10] S. J. An, J. Li, C. Daniel, D. Mohanty, S. Nagpure, and D. L. Wood, "The state of understanding of the lithium-ion-battery graphite solid electrolyte interphase (SEI) and its relationship to formation cycling," Carbon N. Y., vol. 105, pp. 52-76, 2016.

[11] K. Edström, T. Gustafsson, and J. O. Thomas, "The cathode-electrolyte interface in the Liion battery," Electrochim. Acta, vol. 50, no. 2-3 SPEC. ISS., pp. 397-403, 2004.

[12] Y.-M. Liu, B. G. Nicolau, J. L. Esbenshade, and A. A. Gewirth, "Characterization of the Cathode Electrolyte Interface in Lithium Ion Batteries by Desorption Electrospray Ionization Mass Spectrometry," Anal. Chem., vol. 88, no. 14, pp. 7171-7177, 2016.

[13] M. Cuisinier, N. Dupré, J. F. Martin, R. Kanno, and D. Guyomard, "Evolution of the LiFePO4 positive electrode interface along cycling monitored by MAS NMR," J. Power Sources, vol. 224, pp. 50-58, 2013.

[14] J. N. Zhang, Q. Li, Y. Wang, J. Zheng, X. Yu, and H. Li, "Dynamic evolution of cathode electrolyte interphase (CEI) on high voltage $\mathrm{LiCoO} 2$ cathode and its interaction with $\mathrm{Li}$ anode," Energy Storage Mater., vol. 14, no. February, pp. 1-7, 2018.

[15] H. Gabrisch, J. Wilcox, and M. M. Doeff, "TEM Study of Fracturing in Spherical and Platelike LiFePO[sub 4] Particles,” Electrochem. Solid-State Lett., vol. 11, no. 3, p. A25, 2008.

[16] D. Wang, X. Wu, Z. Wang, and L. Chen, "Cracking causing cyclic instability of LiFePO4 cathode material," J. Power Sources, vol. 140, no. 1, pp. 125-128, 2005.

[17] R. Scipioni et al., "Electron microscopy investigations of changes in morphology and conductivity of LiFePO4 / C electrodes," J. Power Sources, vol. 307, pp. 259-269, 2016. 
[18] D. T. Ngo, R. Scipioni, S. B. Simonsen, P. S. Jørgensen, and S. H. Jensen, “A TEM study of morphological and structural degradation phenomena in LiFePO4-CB cathodes," Int. J. Energy Res., vol. 40, no. 14, pp. 2022-2032, 2016.

[19] L. Zou, F. Kang, Y. Zheng, and W. Shen, "Modified natural flake graphite with high cycle performance as anode material in lithium ion batteries," Electrochim. Acta, vol. 54, pp. 3930-3934, 2009.

[20] H. Zheng and M.-S. Kim, "Performance of modified graphite as anode material for lithiumion secondary battery," Carbon Lett., vol. 12, no. 4, pp. 243-248, 2011.

[21] R. Dedryvère et al., "Surface film formation on electrodes in a LiCoO2/graphite cell: A step by step XPS study," J. Power Sources, vol. 174, no. 2, pp. 462-468, 2007.

[22] M. Hellqvist Kjell, S. Malmgren, K. Ciosek, M. Behm, K. Edström, and G. Lindbergh, "Comparing aging of graphite/LiFePO4 cells at $22 \mathrm{C}$ and $55 \mathrm{C}$ - Electrochemical and photoelectron spectroscopy studies," J. Power Sources, vol. 243, pp. 290-298, 2013.

[23] M. Safari and C. Delacourt, "Aging of a Commercial Graphite/LiFePO4 Cell," J. Electrochem. Soc., vol. 158, no. 10, p. A1123, 2011.

[24] J. Wang et al., "Cycle-life model for graphite-LiFePO4 cells," J. Power Sources, vol. 196, no. 8, pp. 3942-3948, 2011.

[25] C. Delacourt and M. Safari, "Life Simulation of a Graphite/LiFePO4 Cell under Cycling and Storage,” J. Electrochem. Soc., vol. 159, no. 8, pp. A1283-A1291, 2012.

[26] E. Sarasketa-Zabala, F. Aguesse, I. Villarreal, L. M. Rodriguez-Martinez, C. M. López, and P. Kubiak, "Understanding lithium inventory loss and sudden performance fade in cylindrical cells during cycling with deep-discharge steps," J. Phys. Chem. C, vol. 119, no. 2, pp. 896906, 2015.

[27] Z. Wang et al., "Effects of cathode electrolyte interfacial (CEI) layer on long term cycling of all-solid-state thin-film batteries," J. Power Sources, vol. 324, pp. 342-348, 2016.

[28] S. Jiao et al., "Stable cycling of high-voltage lithium metal batteries in ether electrolytes," Nat. Energy, 2018.

[29] K. Thydén, Y. L. Liu, and J. B. Bilde-Sørensen, "Microstructural characterization of SOFC Ni-YSZ anode composites by low-voltage scanning electron microscopy," Solid State Ionics, vol. 178, no. 39-40, pp. 1984-1989, 2008.

[30] R. Scipioni, P. S. Jørgensen, D. T. Ngo, S. B. Simonsen, J. Hjelm, P. Norby, and S. H. Jensen, "Low-voltage FIB/SEM Tomography for 3D Microstructure Evolution of LiFePO4/C Electrode,” ECS Trans., vol. 69, no. 18, pp. 71-80, 2015.

[31] M. Dubarry, V. Svoboda, R. Hwu, and B. Yann Liaw, "Incremental Capacity Analysis and Close-to-Equilibrium OCV Measurements to Quantify Capacity Fade in Commercial Rechargeable Lithium Batteries," Electrochem. Solid-State Lett., vol. 9, no. 10, p. A454, 2006.

[32] Y. Jiang, J. Jiang, C. Zhang, W. Zhang, Y. Gao, and Q. Guo, "Recognition of battery aging 
variations for LiFePO4batteries in 2nd use applications combining incremental capacity analysis and statistical approaches," J. Power Sources, vol. 360, pp. 180-188, 2017.

[33] M. Dubarry, C. Truchot, and B. Y. Liaw, "Synthesize battery degradation modes via a diagnostic and prognostic model," J. Power Sources, vol. 219, pp. 204-216, 2012.

[34] R. Scipioni, P. S. Jørgensen, C. Graves, J. Hjelm, and S. H. Jensen, “A Physically-Based Equivalent Circuit Model for the Impedance of a $\mathrm{LiFePO}_{4} /$ Graphite 26650 Cylindrical Cell," J. Electrochem. Soc., vol. 164, no. 9, pp. A2017-A2030, 2017.

[35] N. Ogihara, S. Kawauchi, C. Okuda, Y. Itou, Y. Takeuchi, and Y. Ukyo, "Theoretical and Experimental Analysis of Porous Electrodes for Lithium-Ion Batteries by Electrochemical Impedance Spectroscopy Using a Symmetric Cell,” vol. 159, no. 7, pp. 1034-1039, 2012.

[36] G. Garcia-Belmonte, F. Fabregat-Santiago, J. Bisquert, M. Yamashita, E. C. Pereira, and S. Castro-Garcia, "Frequency dispersion in electrochromic devices and conducting polymer electrodes: A generalized transmission line approach," Ionics (Kiel)., vol. 5, pp. 44-51, 1999.

[37] R. D. Levie, “On porous electrodes," Electrochim. Acta, vol. 9, no. November 1963, p. 1231, 1964.

[38] J. P. Meyers, M. Doyle, R. M. Darling, and J. Newman, "The Impedance Response of a Porous Electrode Composed of Intercalation Particles," J. Electrochem. Soc., vol. 147, no. 8, p. 2930, 2000.

[39] M. Ender, J. Joos, T. Carraro, and E. Ivers-Tiffee, "Quantitative Characterization of LiFePO4 Cathodes Reconstructed by FIB/SEM Tomography," J. Electrochem. Soc., vol. 159, no. 7, pp. A972-A980, 2012.

[40] J. Cazaux, "About the mechanisms of charging in EPMA, SEM, and ESEM with their time evolution.," Microsc. Microanal., vol. 10, no. 6, pp. 670-684, 2004.

[41] D. J. Stokes, "Recent advances in electron imaging, image interpretation and applications: environmental scanning electron microscopy.," Philos. Trans. A. Math. Phys. Eng. Sci., vol. 361 , no. 1813 , pp. 2771-2787, 2003.

[42] J. Sauvola and M. Pietikäinen, "Adaptive document image binarization," Pattern Recognit., vol. 33, no. 2, pp. 225-236, 2000.

[43] T. Kryjak and M. Gorgoń, "Parallel implementation of local thresholding in Mitrion-C," Int. J. Appl. Math. Comput. Sci., vol. 20, no. 3, pp. 571-580, 2010.

[44] B. Münch and L. Holzer, "Contradicting geometrical concepts in pore size analysis attained with electron microscopy and mercury intrusion," J. Am. Ceram. Soc., vol. 91, no. 12, pp. 4059-4067, 2008.

[45] K. Ståhl, "Winpow." http://www.kemi.dtu.dk/english/Research/PhysicalChemistry/Protein_og_roentgenkrystallog rafi/Computer_Programs, 2016.

[46] A. Padhi, K. Nanjundaswamy, and J. Goodenough, "Phospho-olivines as positive-electrode materials for rechargeable lithium batteries," J. Electrochem. Soc., vol. 144, no. 4, 1997. 
[47] A. Andersson, "Lithium extraction/insertion in LiFePO4: an X-ray diffraction and Mössbauer spectroscopy study," Solid State Ionics, vol. 130, no. 1-2, pp. 41-52, May 2000.

[48] S. Torai, M. Nakagomi, S. Yoshitake, S. Yamaguchi, and N. Oyama, "State-of-health estimation of LiFePO4/graphite batteries based on a model using differential capacity," $J$. Power Sources, vol. 306, pp. 62-69, 2016.

[49] J. Illig, M. Ender, T. Chrobak, J. P. Schmidt, D. Klotz, and E. Ivers-Tiffee, "Separation of Charge Transfer and Contact Resistance in LiFePO4-Cathodes by Impedance Modeling," $J$. Electrochem. Soc., vol. 159, no. 7, pp. A952-A960, 2012.

[50] M. Gaberscek, J. Moskon, B. Erjavec, R. Dominko, and J. Jamnik, “The Importance of Interphase Contacts in Li Ion Electrodes: The Meaning of the High-Frequency Impedance Arc," Electrochem. Solid-State Lett., vol. 11, p. A170, 2008.

[51] R. Younesi, M. Hahlin, M. Roberts, and K. Edstr??m, "The SEI layer formed on lithium metal in the presence of oxygen: A seldom considered component in the development of the Li-O2 battery," J. Power Sources, vol. 225, pp. 40-45, 2013.

[52] R. Younesi et al., "Analysis of the Interphase on Carbon Black Formed in High Voltage Batteries," J. Electrochem. Soc., vol. 162, no. 7, pp. A1289-A1296, 2015.

[53] S. Komaba et al., "Electrochemical $\mathrm{Na}$ insertion and solid electrolyte interphase for hardcarbon electrodes and application to Na-ion batteries," Adv. Funct. Mater., vol. 21, no. 20, pp. 3859-3867, 2011.

[54] R. Mogensen, J. Maibach, W. R. Brant, D. Brandell, and R. Younesi, "Evolution of the solid electrolyte interphase on tin phosphide anodes in sodium ion batteries probed by hard x-ray photoelectron spectroscopy," Electrochim. Acta, vol. 245, pp. 696-704, 2017.

[55] M. Klett et al., "Non-uniform aging of cycled commercial LiFePO4//graphite cylindrical cells revealed by post-mortem analysis," J. Power Sources, vol. 257, pp. 126-137, 2014.

[56] L. Zhao, I. Watanabe, T. Doi, S. Okada, and J. ichi Yamaki, "TG-MS analysis of solid electrolyte interphase (SEI) on graphite negative-electrode in lithium-ion batteries," J. Power Sources, vol. 161, no. 2, pp. 1275-1280, 2006.

[57] M. H. Ryou et al., "Effects of lithium salts on thermal stabilities of lithium alkyl carbonates in SEI layer," Electrochim. Acta, vol. 83, pp. 259-263, 2012.

[58] L. H. Saw, Y. Ye, and A. A. O. Tay, "Electrochemical-thermal analysis of 18650 Lithium Iron Phosphate cell," Energy Convers. Manag., vol. 75, pp. 162-174, 2013.

[59] V. Agubra and J. Fergus, "Lithium ion battery anode aging mechanisms," Materials (Basel)., vol. 6, no. 4, pp. 1310-1325, 2013.

[60] S. J. Harris, E. K. Rahani, and V. B. Shenoy, "Direct In Situ Observation and Numerical Simulations of Non-Shrinking-Core Behavior in an MCMB Graphite Composite Electrode," J. Electrochem. Soc., vol. 159, no. 9, pp. A1501-A1507, 2012.

[61] S. Malmgren et al., "Consequences of air exposure on the lithiated graphite SEI," Electrochim. Acta, vol. 105, pp. 83-91, 2013. 
[62] D. Liu et al., "On the stress characteristics of graphite anode in commercial pouch lithiumion battery," J. Power Sources, vol. 232, pp. 29-33, 2013.

[63] S. Bhattacharya, A. R. Riahi, and A. T. Alpas, "A transmission electron microscopy study of crack formation and propagation in electrochemically cycled graphite electrode in lithiumion cells," J. Power Sources, vol. 196, no. 20, pp. 8719-8727, 2011.

[64] C. Shen, S. Wang, Y. Jin, and W. Q. Han, "In Situ AFM Imaging of Solid Electrolyte Interfaces on HOPG with Ethylene Carbonate and Fluoroethylene Carbonate-Based Electrolytes," ACS Appl. Mater. Interfaces, vol. 7, no. 45, pp. 25441-25447, 2015.

[65] S. C. Nagpure, B. Bhushan, and S. S. Babu, "Multi-Scale Characterization Studies of Aged Li-Ion Large Format Cells for Improved Performance: An Overview," J. Electrochem. Soc., vol. 160, no. 11, pp. A2111-A2154, 2013.

[66] V. a. Agubra and J. W. Fergus, "The formation and stability of the solid electrolyte interface on the graphite anode," J. Power Sources, vol. 268, pp. 153-162, 2014.

[67] C. Pastor-Fernández, K. Uddin, G. H. Chouchelamane, W. D. Widanage, and J. Marco, “A Comparison between Electrochemical Impedance Spectroscopy and Incremental CapacityDifferential Voltage as Li-ion Diagnostic Techniques to Identify and Quantify the Effects of Degradation Modes within Battery Management Systems," J. Power Sources, vol. 360, pp. 301-318, 2017.

[68] C. Zhu et al., "Lithium potential variations for metastable materials: Case study of nanocrystalline and amorphous LiFePO4," Nano Lett., vol. 14, no. 9, pp. 5342-5349, 2014.

[69] M. Gu, W. Shi, J. Zheng, P. Yan, J. Zhang, and C. Wang, "Probing the failure mechanism of nanoscale LiFePO ${ }_{4}$ for Li-ion batteries," Appl. Phys. Lett., vol. 106, no. 20, p. 203902, 2015.

[70] A. Barré, B. Deguilhem, S. Grolleau, M. Gérard, F. Suard, and D. Riu, "A review on lithiumion battery ageing mechanisms and estimations for automotive applications," J. Power Sources, vol. 241, pp. 680-689, 2013.

[71] L. Tan, L. Zhang, Q. Sun, M. Shen, Q. Qu, and H. Zheng, "Capacity loss induced by lithium deposition at graphite anode for LiFePO4/graphite cell cycling at different temperatures," Electrochim. Acta, vol. 111, pp. 802-808, 2013.

[72] D. Aurbach, E. Zinigrad, Y. Cohen, and H. Teller, "A short review of failure mechanisms of lithium metal and lithiated graphite anodes in liquid electrolyte solutions," in Solid State Ionics, 2002, vol. 148, no. 3-4, pp. 405-416.

[73] C. M. López, J. T. Vaughey, and D. W. Dees, "Insights into the Role of Interphasial Morphology on the Electrochemical Performance of Lithium Electrodes," J. Electrochem. Soc., vol. 159, no. 6, p. A873, 2012. 


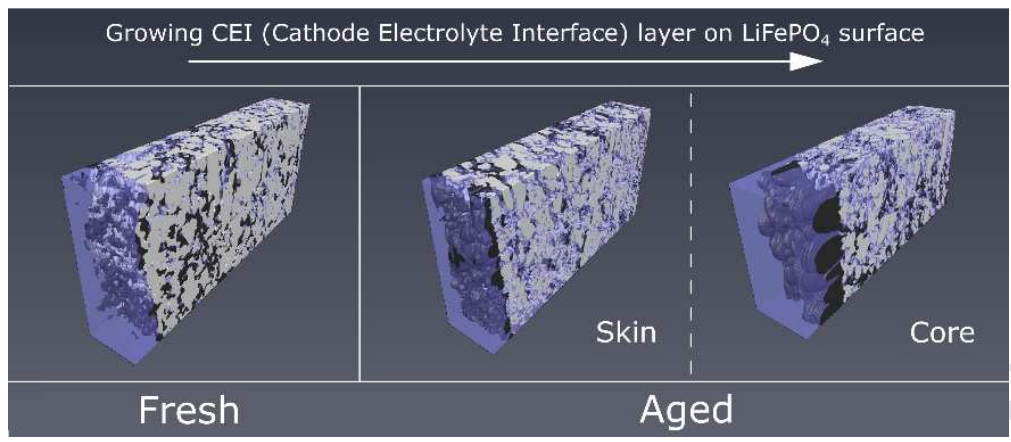

\section{FIGURES}
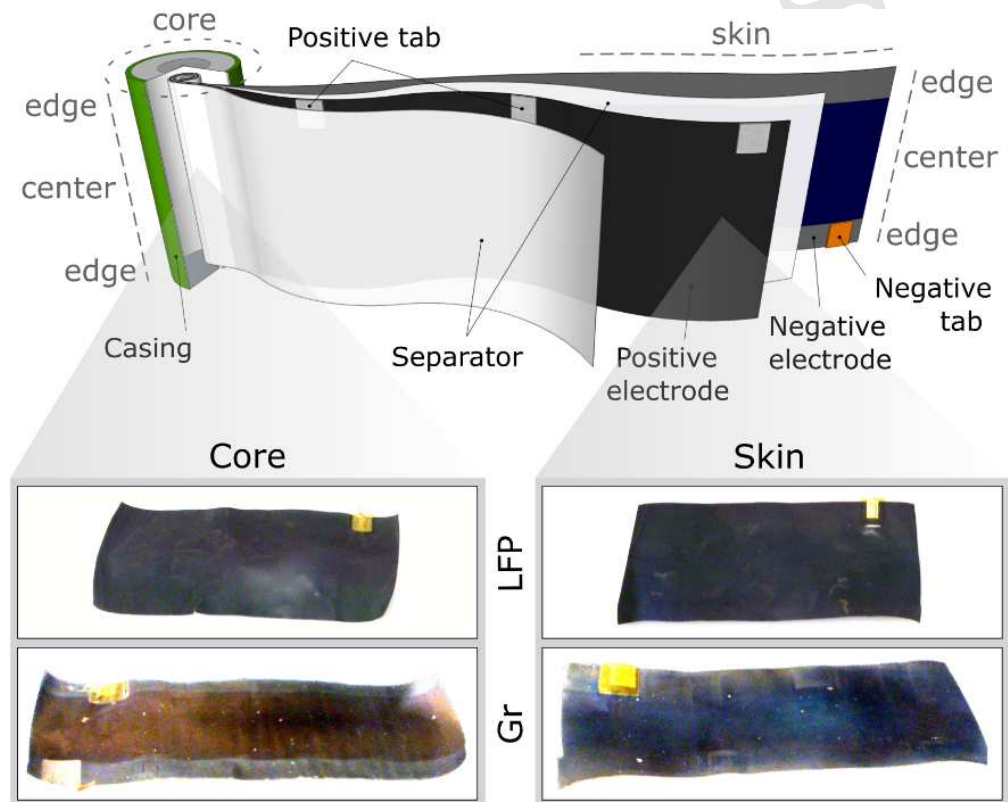

Figure 1 


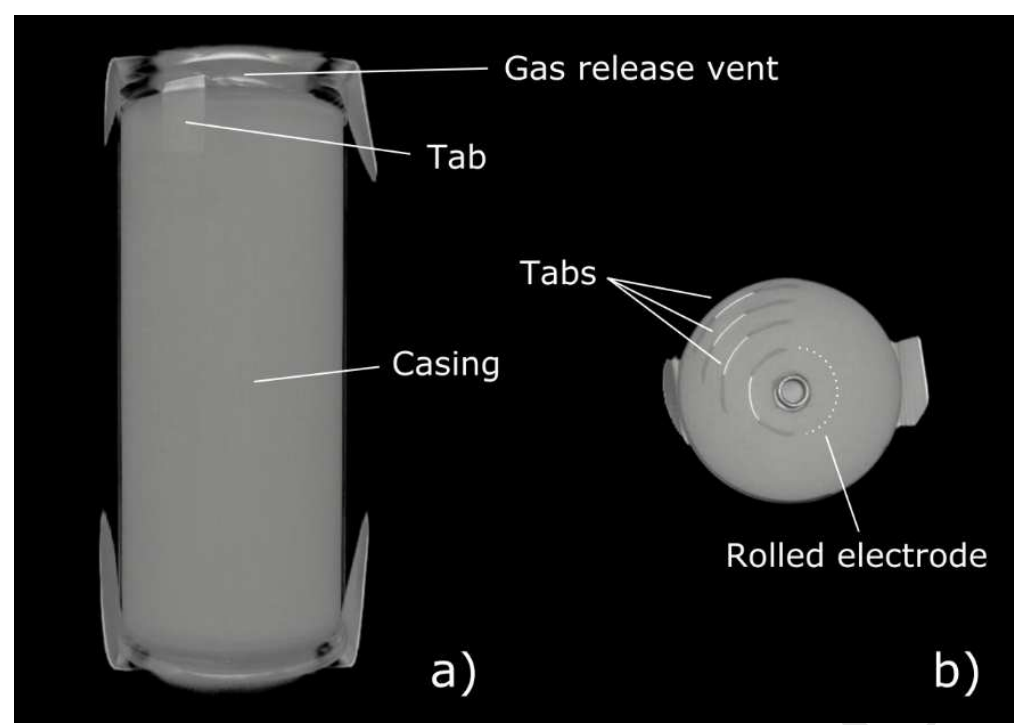

Figure 2
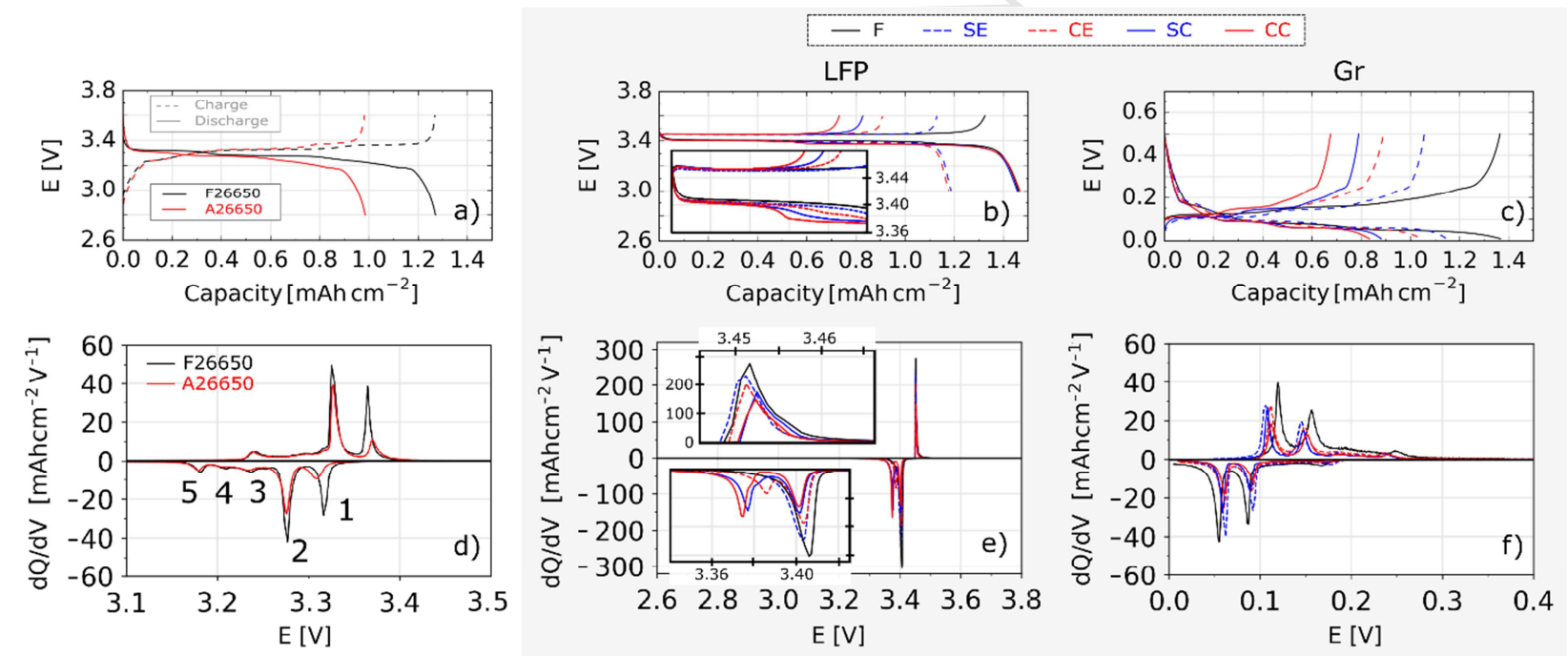

Figure 3 

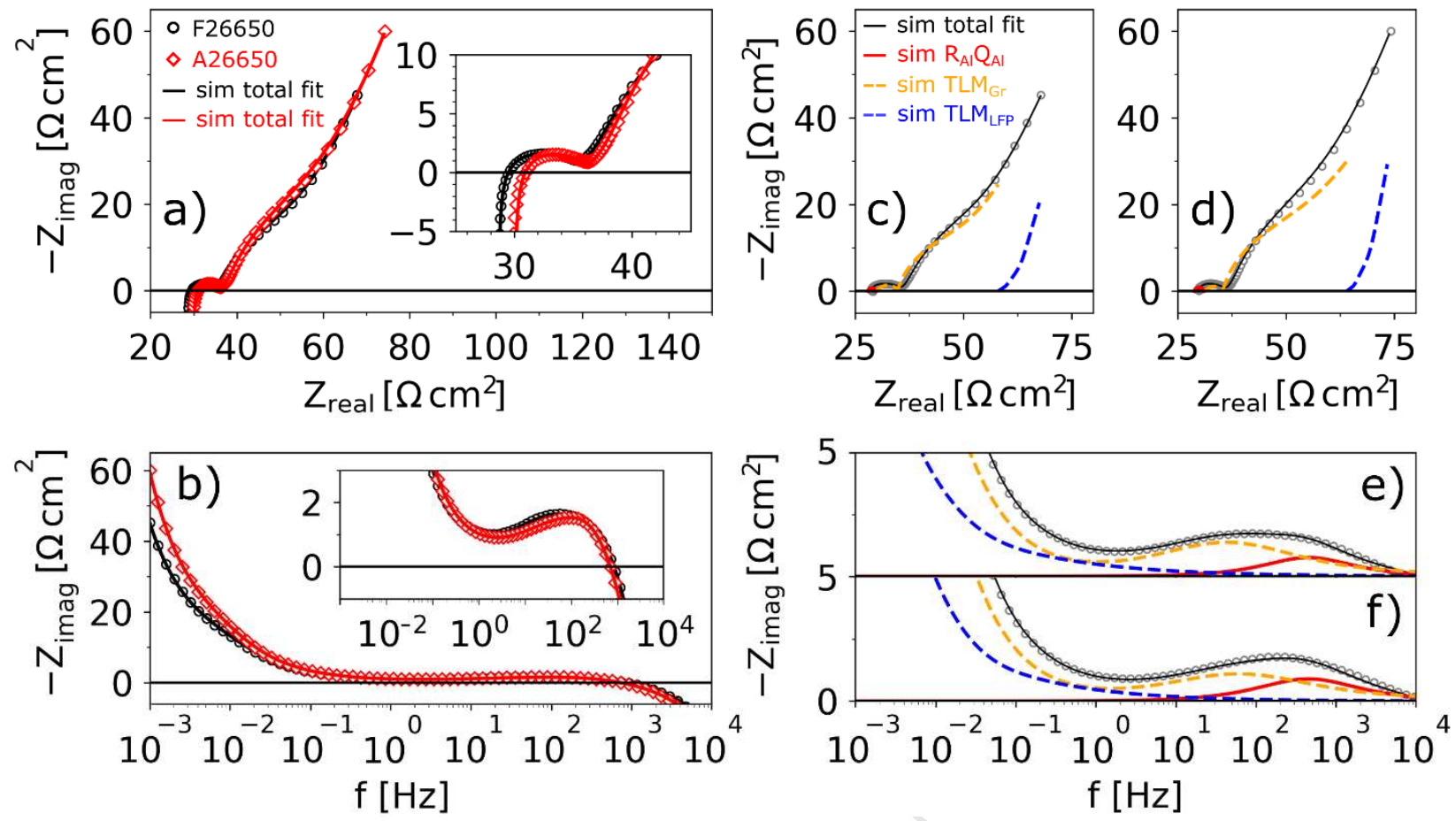

Figure 4

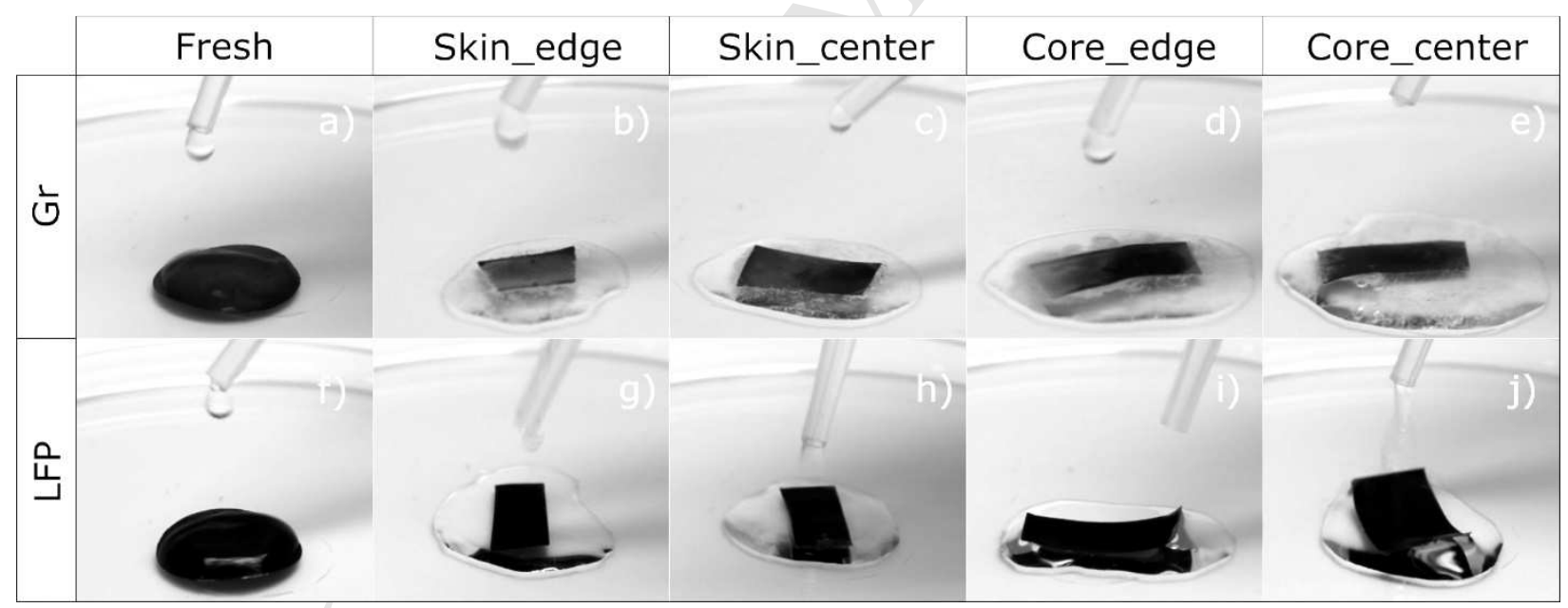

Figure 5 


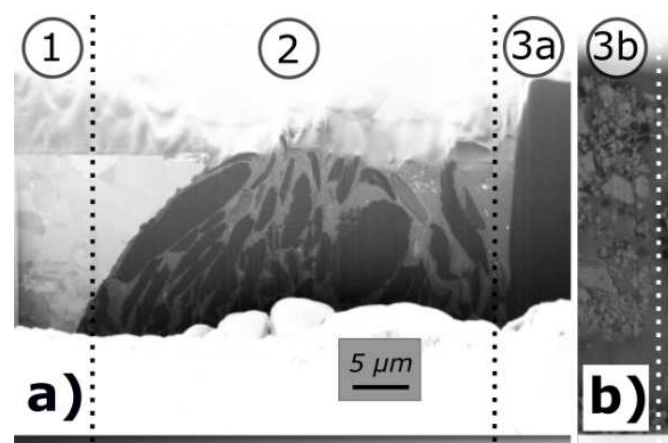

(4)

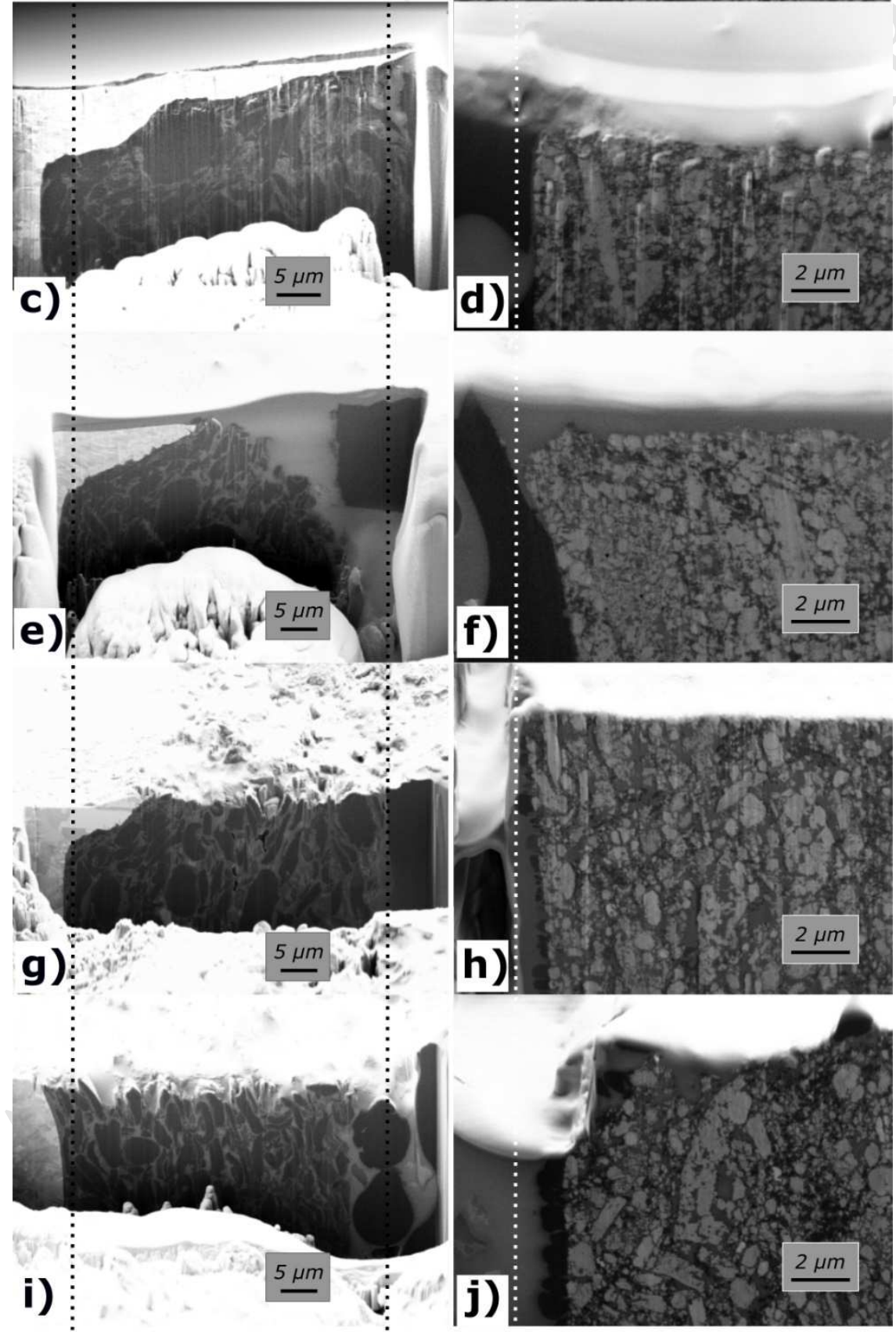

Figure 6 


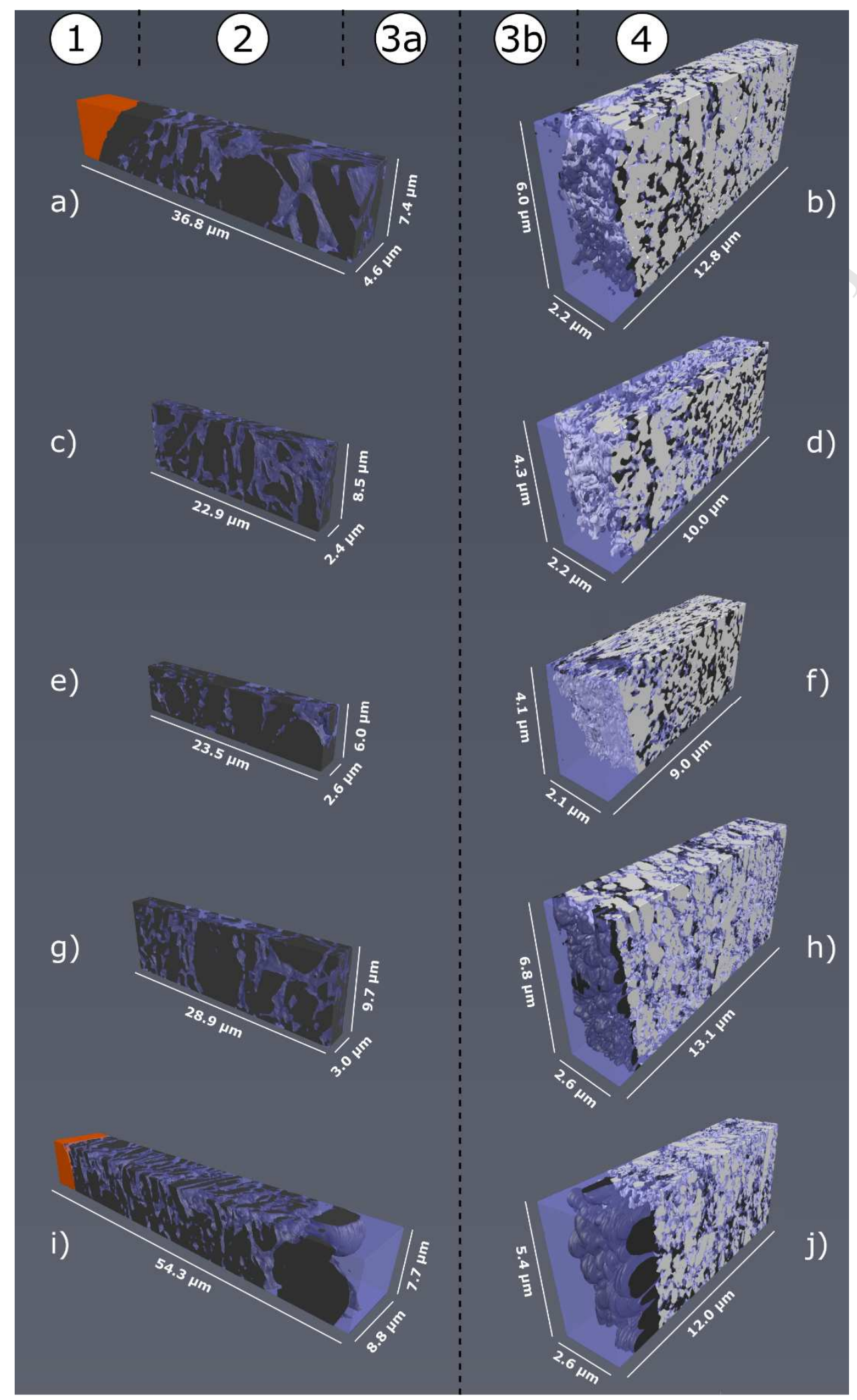

Figure 7 

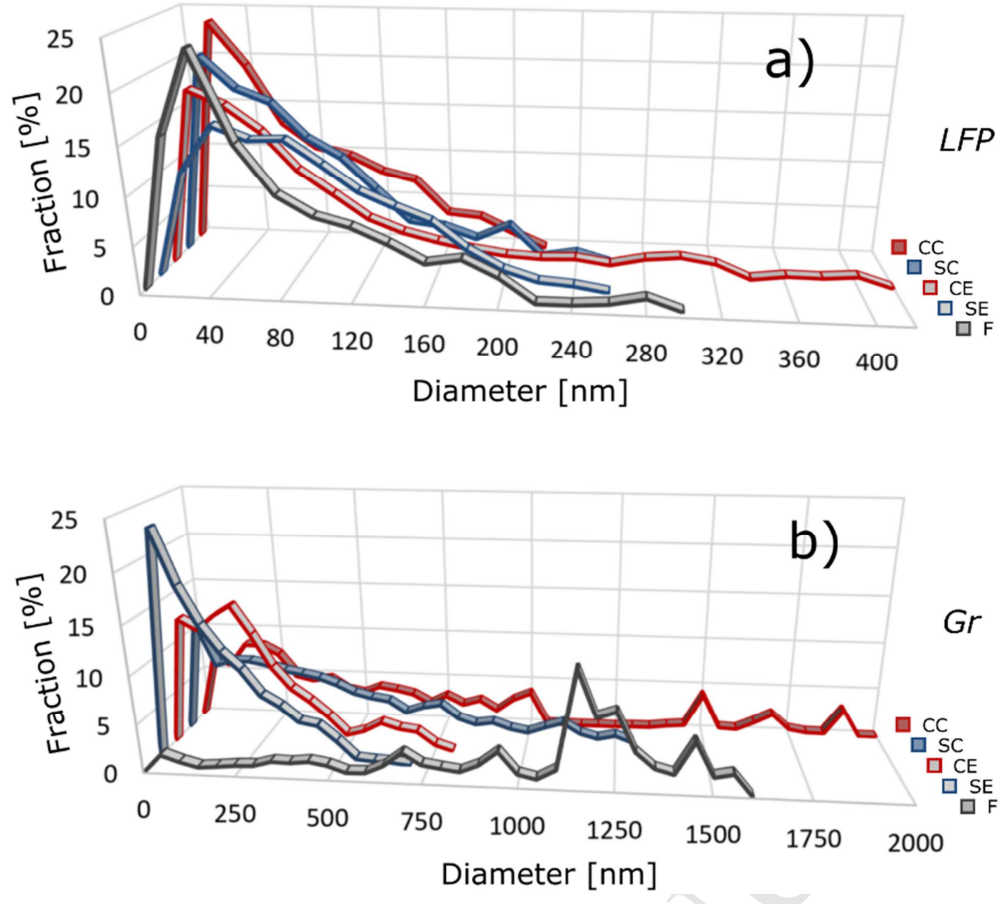

Figure 8

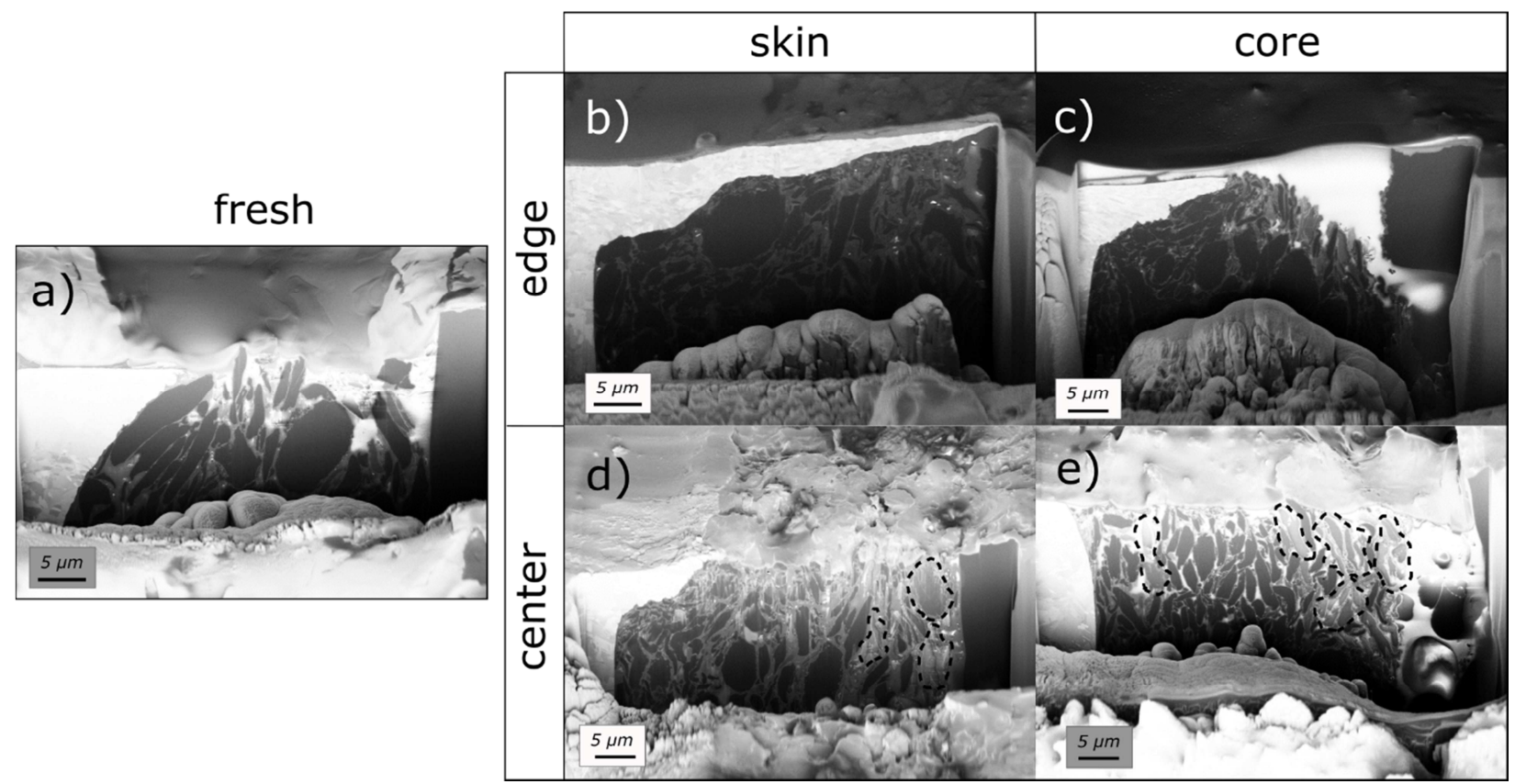

Figure 9 


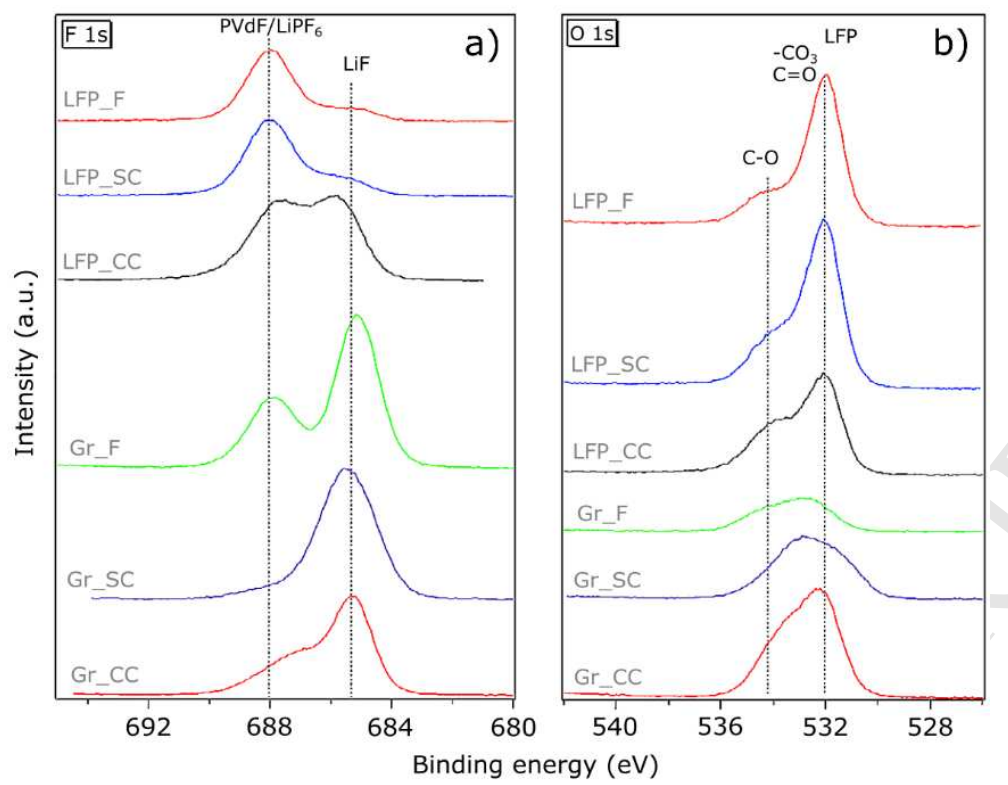

Figure 10
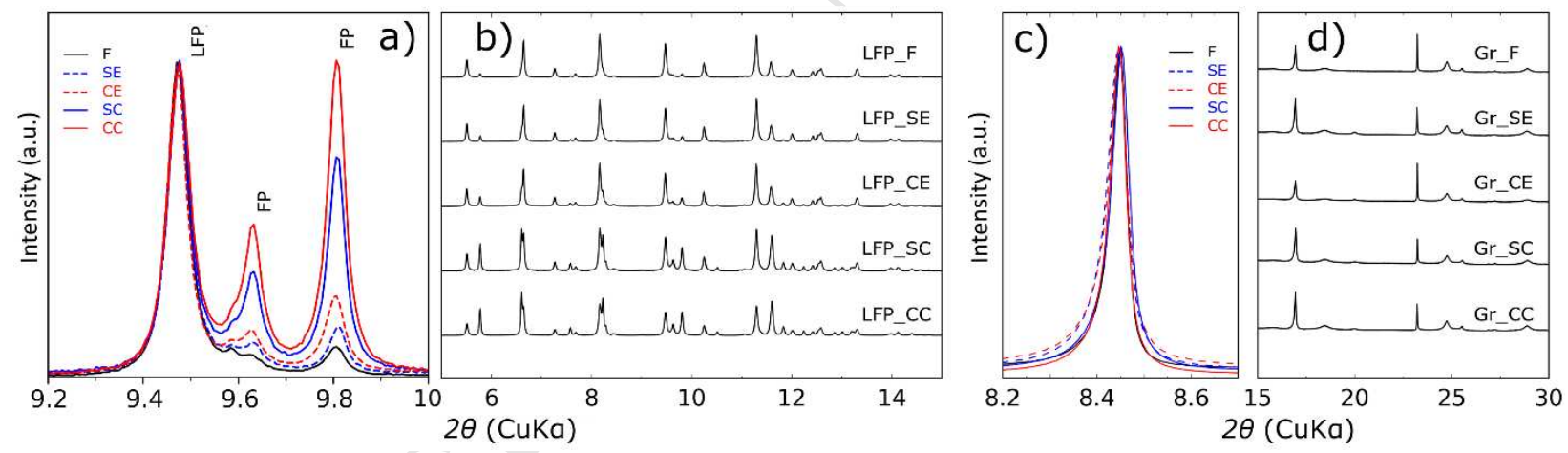

Figure 11 

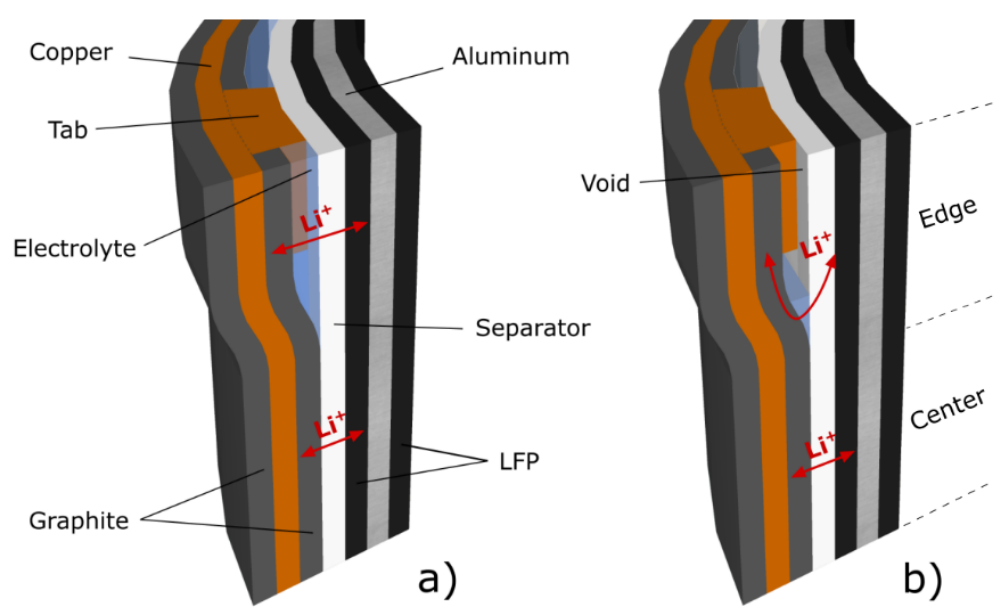

Figure 12 


\section{FIGURE CAPTIONS}

Figure 1. Schematic representation of the unrolled $26650 \mathrm{LiFePO}_{4} / \mathrm{Graphite}$ battery packaging design (on the top). Photos of the four pieces of the aged $\mathrm{Li}_{1-\mathrm{x}} \mathrm{FePO}_{4}$ and $\mathrm{Li}_{\mathrm{x}} \mathrm{C}_{6}$ negative electrode (on the bottom). The images have increased color saturation to emphasize the color difference.

Figure 2. X-ray tomogram of a) F26650 and b) cross-section.

Figure 3. Charge/Discharge curves of a) F26650 and A26650, b) LFP electrodes and c) Gr electrodes. d-f) Corresponding Incremental Capacity curves of a-c). The fresh samples in b,c) are labeled with "_F" and the aged ones with respect to their original position in the foil: E.g. "_CE" refer to "Core, Edge" whereas "_SC" refer to "Skin, Center"

Figure 4. a) Nyquist and b) Bode plot of the fresh and aged cylindrical cells at 50\% SOC. The insets show rescaled Nyquist and Bode plots to highlight the high-frequency part of the spectra. Nyquist plots and relative fittings of c) fresh and d) aged cell at 50\% SOC. Zoomed view of Bode plots and relative fittings of e) fresh and f) aged cell at 50\% SOC.

Figure 5. a) Fresh and b-e) aged Gr electrodes after water addition. f) Fresh and g-j) aged LFP electrodes after water addition.

Figure 6. SEM images at $1 \mathrm{kV}$ recorded with Lateral $\mathrm{E}$ - T detector of a) Gr_F, b) LFP_F, c) Gr_SE, d) LFP_SE, e) Gr_CE, f) LFP_CE, g) Gr_SC, h) LFP_SC, i) Gr_CC, and j) LFP_CC.

Figure 7.3D reconstructions of the segmented datasets: a) Gr_F, b) LFP_F, c) Gr_SE, d) LFP_SE, e) Gr_CE, f) LFP_CE, g) Gr_SC, h) LFP_SC, i) Gr_CC, and j) LFP_CC.

Figure 8. Particle size distributions for the various samples mentioned in Table 1. 
Figure 9. SEM images at $1 \mathrm{kV}$ recorded with In-lens detector of a) Gr_F, b) Gr_SE, c) Gr_CE, d) Gr_SC, and e) Gr_CC electrodes. The black dotted circles highlight particles appearing brighter, supposedly charging, thus partially disconnected, particles. This phenomenon is in particular seen in the degraded electrode samples.

Figure 10. a) F1s and b) O1s spectra of fresh, skin center and core center samples.

Figure 11. XRD patterns from a-b) LFP electrodes and c-d) Gr electrodes. The intensities in a) were normalized to the (020) reflection in LFP. The intensities in b), c) and d) were normalized to the strongest peak

Figure 12. Schematic representation of the ionic pathways at the center and the edge of the electrodes in the a) fresh and b) aged battery roll. 
Table 4. Results from EIS fitting of F26650 and A26650 at 50\% SOC.

\begin{tabular}{|c|c|c|c|c|c|c|c|c|c|c|c|c|c|c|}
\hline & \multirow{3}{*}{$\begin{array}{c}\mathbf{R}_{\mathbf{E}} \\
\boldsymbol{R}_{\boldsymbol{E}} \\
\left(\Omega \mathrm{cm}^{2}\right) \\
\end{array}$} & \multirow{2}{*}{\multicolumn{2}{|c|}{$\mathbf{R}_{\mathrm{Al}} \mathbf{Q}_{\mathrm{Al}}$ element }} & \multicolumn{6}{|c|}{ Transmission Line Graphite } & \multicolumn{5}{|c|}{ Transmission Line $\mathrm{LiFePO}_{4}$} \\
\hline & & & & \multicolumn{5}{|c|}{ Meyers element } & \multirow{2}{*}{$\begin{array}{c}\text { Pores } \\
\boldsymbol{R}_{\text {ion }, \mathrm{L}} \\
(\Omega \mathrm{cm}) \\
\end{array}$} & \multicolumn{3}{|c|}{ Randles element } & \multirow{2}{*}{$\begin{array}{c}\text { Pores } \\
\boldsymbol{R}_{\text {ion }, \mathrm{L}} \\
(\Omega \mathrm{cm}) \\
\end{array}$} & \multirow{2}{*}{$\begin{array}{c}\text { Electrode } \\
\boldsymbol{R}_{e l} \\
(\Omega c m)\end{array}$} \\
\hline & & $\begin{array}{c}\boldsymbol{R}_{\boldsymbol{A l}} \\
\left(\Omega \mathrm{cm}^{2}\right)\end{array}$ & $\begin{array}{c}\boldsymbol{C}_{\boldsymbol{A l}} \\
\left(\mathrm{mFcm} \mathrm{F}^{-2}\right)\end{array}$ & $\begin{array}{c}\boldsymbol{R}_{S E I} \\
\left(\Omega \mathrm{cm}^{2}\right)\end{array}$ & $\begin{array}{c}\boldsymbol{C}_{\boldsymbol{S E I}} \\
\left(\mathrm{mFcm}^{-2}\right)\end{array}$ & $\begin{array}{c}\boldsymbol{R}_{\boldsymbol{c t}} \\
\left(\Omega \mathrm{cm}^{2}\right)\end{array}$ & $\begin{array}{c}\boldsymbol{C}_{\text {dll }} \\
\left(\mathrm{Fcm}^{-2}\right)\end{array}$ & $\begin{array}{c}\boldsymbol{D} \\
\left(\mathrm{cm}^{2} \mathrm{~s}^{-1}\right)\end{array}$ & & $\begin{array}{c}\boldsymbol{R}_{\boldsymbol{c t}} \\
\left(\Omega \mathrm{sm}^{2}\right)\end{array}$ & $\begin{array}{c}\boldsymbol{C}_{\boldsymbol{d l}} \\
\left(\mathrm{Fcm}^{-2}\right)\end{array}$ & $\begin{array}{c}\boldsymbol{D} \\
\left(\mathrm{cm}^{2} \mathrm{~s}^{-1}\right)\end{array}$ & & \\
\hline F26650 & 28.0 & 1.74 & 0.20 & 4.77 & 0.36 & 23.6 & 0.78 & $4.8 \cdot 10^{-11}$ & 321 & 11.9 & 1.80 & $2.4 \cdot 10^{-13}$ & 810 & 40 \\
\hline A26650 & 29.2 & 2.12 & 0.24 & 4.10 & 0.38 & 31.1 & 0.67 & $6.6 \cdot 10^{-12}$ & 312 & 13.2 & 2.07 & $2.4 \cdot 10^{-13}$ & 864 & 66 \\
\hline
\end{tabular}

Table 5. Average particle diameters for the electrodes.

\begin{tabular}{c|c|c|c|c|c|}
\cline { 2 - 6 } Phase & \multicolumn{4}{|c|}{ Average diameter [nm] } \\
\cline { 2 - 6 } & Fresh & \multicolumn{2}{|c|}{ Edge } & \multicolumn{2}{c|}{ Center } \\
\cline { 2 - 6 } & F & SE & CE & SC & CC \\
\cline { 2 - 6 } & \multicolumn{5}{|c|}{ LFP } \\
\hline LiFePO $_{4}$ & 76 & 77 & 80 & 71 & 68 \\
$\mathrm{CB}$ Additive $^{*}$ & 49 & 30 & 25 & 28 & 42 \\
Pores & 39 & 18 & 15 & 45 & 48 \\
\hline Agglomerates & - & - & - & 141 & 169 \\
\hline & \multicolumn{5}{|c|}{ Gr } \\
\hline Graphite & 1096 & 158 & 217 & 370 & 564 \\
Pores & 159 & 128 & 69 & 220 & 302 \\
\hline Agglomerates & - & - & - & - & 875 \\
\hline
\end{tabular}

Table 6. Unit cell parameters of LFP and Gr electrodes (the standard deviations given are from the Rietveld refinement and are therefore underestimated).

\begin{tabular}{|c|c|c|c|c|c|c|}
\hline & & $\mathbf{a}[\AA ̊]$ & $\mathbf{b}$ [̊̊] & c [̊̊] & $\mathbf{V}\left[\AA^{3}\right]$ & Fraction [mol.\%] \\
\hline \multirow{12}{*}{ 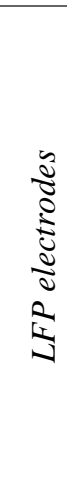 } & $\mathrm{LiFePO}_{4}$ & & & & & \\
\hline & $F$ & $10.3044(3)$ & $5.9944(2)$ & $4.6958(1)$ & $290.06(3)$ & 90.3 \\
\hline & $S E$ & $10.3034(3)$ & $5.9926(2)$ & $4.6937(1)$ & 289.81(2) & 86.9 \\
\hline & $C E$ & $10.3068(3)$ & $5.9948(2)$ & $4.6956(1)$ & $290.13(2)$ & 77.7 \\
\hline & $S C$ & $10.3017(3)$ & $5.9929(2)$ & $4.6960(1)$ & $289.92(2)$ & 60.8 \\
\hline & $C C$ & 10.2991(3) & $5.9915(2)$ & $4.6954(2)$ & 289.74(3) & 51.8 \\
\hline & $\mathrm{FePO}_{4}$ & 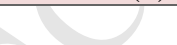 & & & & \\
\hline & $F$ & $9.8305(10)$ & $5.7953(4)$ & $4.7791(4)$ & $272.27(7)$ & 9.7 \\
\hline & $S E$ & $9.8225(7)$ & $5.7905(3)$ & 4.7791(3) & $271.82(5)$ & 13.1 \\
\hline & $C E$ & $9.8285(4)$ & $5.7939(2)$ & $4.7808(2)$ & $272.24(3)$ & 22.3 \\
\hline & $S C$ & $9.8255(3)$ & $5.7923(2)$ & $4.7804(1)$ & $272.07(2)$ & 39.2 \\
\hline & $C C$ & $9.8242(3)$ & $5.7912(2)$ & $4.7793(2)$ & 271.91(3) & 48.2 \\
\hline \multirow{6}{*}{ 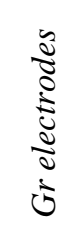 } & Graphite & & & & & \\
\hline & $F$ & $2.4596(1)$ & - & $6.7284(2)$ & $35.25(1)$ & $\sim 100 \%$ \\
\hline & $S E$ & $2.4585(9)$ & - & $6.7316(8)$ & $35.24(4)$ & $\sim 100 \%$ \\
\hline & $C E$ & $2.4591(1)$ & - & $6.7330(1)$ & $35.26(1)$ & $\sim 100 \%$ \\
\hline & $S C$ & $2.4582(1)$ & - & $6.7267(3)$ & $35.20(1)$ & $\sim 100 \%$ \\
\hline & $C C$ & $2.4580(7)$ & - & $6.7245(1)$ & $35.19(2)$ & $\sim 100 \%$ \\
\hline
\end{tabular}

